\title{
Identification of Motoneurons and Interneurons in the Spinal Network for Escapes Initiated by the Mauthner Cell in Goldfish
}

\author{
Joseph R. Fetcho and Donald S. Faber \\ Neurobiology Laboratory, Department of Physiology, State University of New York at Buffalo, Buffalo, New York 14214
}

We used intracellular recording and staining techniques to study the spinal circuitry of the escape behavior (C-start) initiated by the Mauthner axon (M-axon) in goldfish. Simultaneous intracellular recordings from one or both $\mathbf{M}$-axons and a spinal neuron, followed by HRP labeling of the spinal cell, show that each M-axon makes monosynaptic, chemical excitatory synapses onto 2 populations of ipsilateral spinal neurons. The first consists of the large primary motoneurons that, based on earlier work (Fetcho, 1986), innervate exclusively the faster, white muscle fiber types in the myomeres. The second group of cells is formed by previously undescribed descending interneurons with ipsilateral axonal branches that have contacts with primary and secondary motoneurons spread over 2 or more body segments. Indirect evidence suggests that these descending interneurons are excitatory, and they may explain the polysynaptic activation of motoneurons observed in earlier studies of the spinal circuitry (Diamond, 1971). Both classes of neurons excited by the ipsilateral M-axon are disynaptically inhibited by the contralateral one. The morphology and physiology indicate that this inhibition is mediated by interneurons that are electrotonically coupled to one $\mathbf{M}$-axon and have processes that cross the cord to inhibit contralateral neurons in the region where these postsynaptic cells receive excitatory input from the other $M$-axon. We have identified inteneurons with the physiological and morphological features of these predicted crossed inhibitory interneurons. These cells are electrotonically coupled to the ipsilateral $\mathrm{M}$-axon and receive a chloride-dependent disynaptic inhibitory input from the contralateral $M$-axon. Their very simple somata give rise to a process that crosses the spinal cord between the $2 \mathrm{M}$-axons. Once on the opposite side of the cord, the crossing process sends myelinated branches that run rostrally and caudally, roughly parallel to the contralateral $\mathrm{M}$-axon. Processes that arise from these longitudinal branches terminate in a striking association with collaterals of the $\mathbf{M}$-axon; nearly every $\mathbf{M}$-axon collateral along the longitudinal course of an interneuron is met by a branch or branches of the interneuron whose terminals are apposed to neurons postsynaptic to the collateral.

The identified cells can account for some of the major features of the escape behavior initiated by the M-cell, including the massive excitation of muscle via mono- and poly-

Received Sept. 30, 1987; revised Feb. 29, 1988; accepted Mar. 14, 1988.

Supported by an NIH Postdoctoral Fellowship (J.R.F.) and NIH Grant NS15335 (D.S.F.).

Correspondence should be addressed to Dr. Joseph R. Fetcho, Neurobiology Lab, Department of Physiology, 313 Cary Hall, State University of New York at Buffalo, Buffalo, NY 14214.

Copyright (C) 1988 Society for Neuroscience $0270-6474 / 88 / 114192-22 \$ 02.00 / 0$ synaptic activation of motoneurons on the side of the active $M-a x o n$ and the inhibition of motoneurons and interneurons on the opposite side. The description of the spinal network that emerges from our work confirms several conclusions from Diamond and Yasargil's early studies of the circuitry (Yasargil and Diamond, 1968; Diamond and Yasargil, 1969; Diamond, 1971), refutes others, and introduces some new neurons in the network. The M-cell circuitry has several similarities with the spinal circuits for swimming in lampreys and anuran embryos. These parallels suggest that many vertebrates might have common arrangements of spinal circuitry, portions of which are involved in such different motor behaviors as escape (C-starts) and swimming.

Many attempts to define the circuitry responsible for motor behaviors in vertebrates have focused on the spinal cord (Grillner et al., 1986b), both because it can generate rhythmic motor behaviors in isolation from the brain and because its smaller number of cells and relative simplicity make it seem less formidable than the brain. Nevetheless, progress in identifying the spinal circuits for motor behaviors has been slow, largely because even these networks contain a substantial number of small neurons that are not easily accessible to the intracellular physiological and morphological techniques necessary for a detailed analysis of the circuitry. Recently, the focus of research on spinal motor circuits has shifted from mammals to anamniotic vertebrates such as lampreys and embryonic and larval fish and frogs, with the hope that the smaller number of neurons in their spinal cords might allow a more complete, cellular-level investigation of motor behaviors. Most of these studies have dealt with the circuitry for rhythmic swimming. They have substantially advanced our understanding of spinal motor circuits in vertebrates by identifying and determining the functional roles of many spinal neurons that are important in swimming (scc Grillner et al., 1986b, for reviews of much of this work).

We have begun to examine the spinal circuitry of another very important motor behavior in fishes and amphibians-the escape behavior initiated by the Mauthner cell. The majority of anamniotic vertebrates have a bilateral pair of neurons called Mauthner cells (M-cells) whose somata lie in the hindbrain and whose axons project down the length of the spinal cord on the side opposite the soma (Zottoli, 1978). These M-cells receive inputs from most sensory modalities, and they initiate a body bend, the $\mathrm{C}$ start, that is used for escape. This escape behavior is characterized by an abrupt, C-shaped bending of the body and tail during which some fish reach accelerations of as much as $5 \mathrm{~g}$ in as little as $20 \mathrm{msec}$ (Webb, 1978; Eaton and Hackett, 1984). The bend rotates the fish about its center of mass, turning it away from a potential threat. After this initial response, the 
bend moves caudally along the body, and the fish glides or swims away.

Although the neural circuitry of portions of this escape behavior is among the best understood networks in vertebrates (Faber and Korn, 1978), most studies of the M-cell have emphasized the cranial portions of the network, including inputs to the M-cell and its outputs to head musculature. Much less is known about the spinal network that produces the characteristic, dramatic tail-flip, which is the most prominent feature of the hehavior. Most of the available data come from the early studies of Diamond and Yasargil (Yasargil and Diamond, 1968; Diamond and Yasargil, 1969; Diamond, 1971). Their work described many major characteristics of the behavior and produced several provocative hypotheses about the spinal network; however, because it was performed prior to the introduction of intracellular staining techniques, the cells studied were not conclusively identified. We have used intracellular staining techniques in conjunction with simultaneous intracellular recordings to study the physiology and morphology of spinal neurons that receive input from the $\mathrm{M}$-axons. The neurons we have identified can account for the major features of the startle behavior, including the massive excitation of axial musculature during the $\mathrm{C}$-bend and the crossed inhibition of neurons on the side opposite the bend. We use our data (1) to evaluate earlier hypotheses about the spinal network; (2) to place our new information in the context of recent studies of the functional organization of axial motoneurons in fish; and (3) to compare the M-cell network to the spinal network for swimming in other anamniotes.

Portions of this work have been presented in abstracts (Fetcho and Faber, 1986a, b, 1987a, b).

\section{Materials and Methods}

Physiology. Goldfish (Carassius auratus; $8-11 \mathrm{~cm}$ standard length) obtained commercially (Grassy Forks Fisheries, Martinsville, IN) were anesthetized by immersion in $0.02 \%$ aqueous tricane methanesulfonate and paralyzed by an intraperitoneal injection of tubocurarine chloride (approximately $0.001 \mathrm{mg} / \mathrm{gm}$ body weight). Portions of the spinal cord from 1 or 2 body segments on the left side of the caudal trunk and tail (at roughly the rostrocaudal location of the anal opening) were exposed by removing, first the dorsolateral epaxial musculature and, then, by laminectomy, portions of the vertebral column. Each fish was mounted in a chamber that allowed constant perfusion of the gills with aerated water containing anesthetic ( $1 \%$ urethane). The tail was pinned firmly, left side up, to a platform, and the Mauthner axons were exposed rostrally between the vagal lobes, where they are visible under a dissecting microscope. The meninges covering the exposed spinal cord on the tail were very carefully removed with a combination of fine glass probes and iridectomy scissors. Bipolar stimulating electrodes were placed on the spinal cord caudal to the exposed spinal segments and also, in some cases, on ventral roots.

Intracellular recordings from the $\mathbf{M}$-axons or spinal neurons were obtained by using standard electrophysiological techniques; the recording arrangement of the intracellular electrodes is diagrammed in Figure 1 . One or both $\mathrm{M}$-axons were impaled with microelectrodes $(2.5 \mathrm{M} \mathrm{KCl}$, 5-10 M $\Omega$ resistance) at a supraspinal level and another microelectrode that contained HRP (resistance, 10-40 M $\Omega$ ) was used to record from spinal neurons or from the M-axons in the caudal spinal cord. The HRP electrodes were produced by backfilling the tip with about $1 \mu 1$ of $2 \%$ Fast green in $2.5 \mathrm{M} \mathrm{KCl}$, followed by $1 \mu 1$ of $10 \%$ HRP (10\% HRP, 2.5 $\mathrm{M} \mathrm{KCl}, 0.05 \mathrm{M}$ Tris, $\mathrm{pH} 8.5$ ) added after the tip was completely filled with the Fast green solution. The electrodes were refrigerated overnight to allow the HRP to diffuse to the tip, and the shanks were backfilled with Fast green solution immediately prior to use. These HRP electrodes were attached to a pressure system for injection of HRP to morphologically label cells studied physiologically.

Spinal neurons contacted by the $\mathrm{M}$-axon were identified by firing one or both M-axons every few seconds through the supraspinal electrodes,

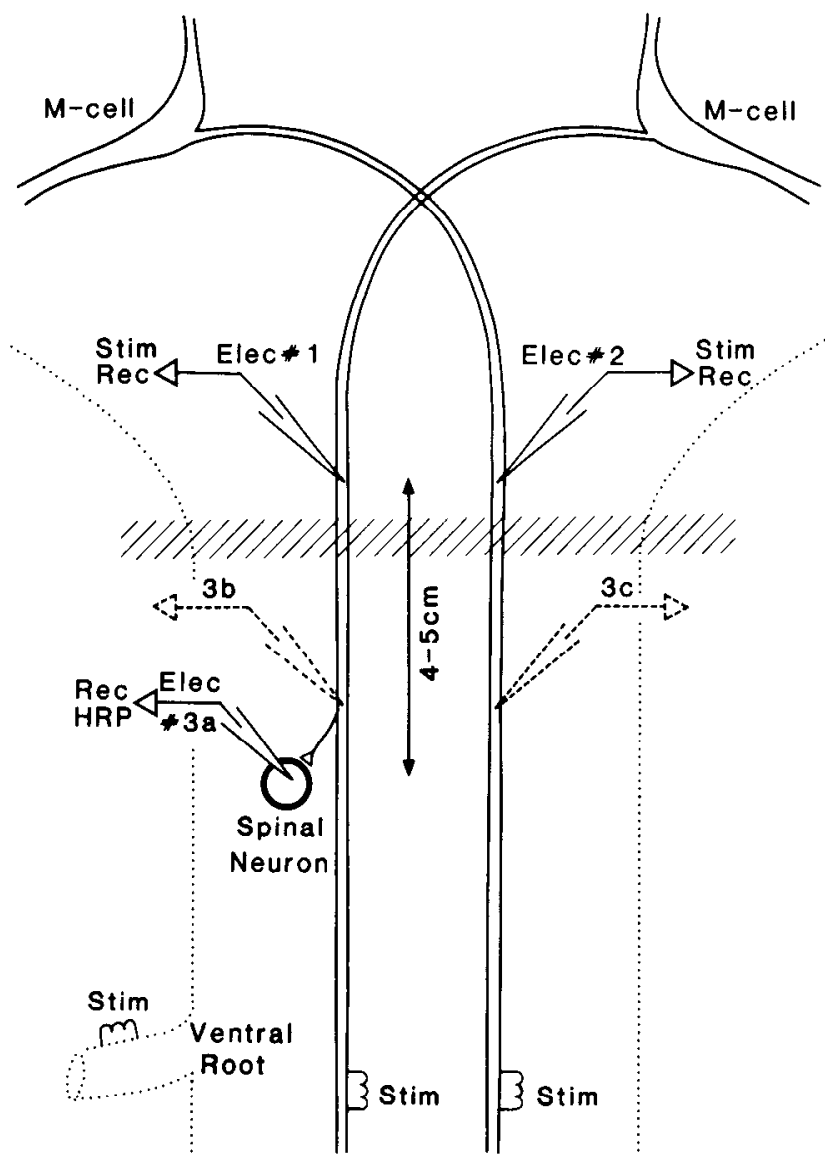

Figure 1. Diagram of the recording arrangement. Intracellular electrodes ( $E l e c$. $\# 1$ and $\# 2$ ) were placed in both M-axons at a supraspinal level, and a third microelectrode containing HRP (Elec. \#3) was uscd to record from either a spinal neuron postsynaptic to the M-axons (\#3a) or the M-axons ( $3 b$ or $3 c$ ) in caudal spinal cord. Stimulating electrodes (Stim) placed on the cord or on ventral roots activated the M-axons or motoneurons antidromically. Hatching marks the separation between supraspinal and spinal recording sites, typically $4-5 \mathrm{~cm}$.

while a segment of caudal spinal cord was systematically searched with the HRP electrode for cells that responded at short latency. In conducting the searches, the M-axon(s) in the spinal segment were first located based on extracellular recordings of their action potentials, and their positions served as reference points as we looked for postsynaptic cells. In early experiments we sampled over the entire dorsoventral extent of the cord; later, our searches were frequently directed toward regions where we found it easiest to record from a particular class of spinal neuron. Once a cell was located and physiological data were collected on film or tape, the neuron was filled with HRP by several brief, manually controlled pressure pulses at 25-35 psi. Successful injections were accompanied by a depolarization of the cell during the pressure pulse followed, at the end of the pulse, by a gradual return toward the original resting potential. After filling a cell, the M-axon(s) in the same segment as the neuron was (were) impaled and identified by stimulating through the caudal electrode to produce an antidromic action potential rostrally. We measured the time required for impulse conduction in the axon from the rostral electrode used to excite it to the caudal spinal segment that contained the postsynaptic neuron. This conduction time was subtracted from the delay between the rostral action potential in the $\mathbf{M}$-axon and the response in the postsynaptic ccll to obtain the synaptic delay at each synapse. All synaptic latencies were measured from the foot of the $\mathrm{M}$-axon action potential in the spinal segment to the beginning of the response in the postsynaptic cell. This latency probably slightly overestimates the true synaptic delay (Llinas and Heuser, 1977). In several experiments, one or both $\mathrm{M}$-axons in the caudal spinal cord were also filled with HRP. These fills confirmed that spinal units identified using the above criterion were always $\mathrm{M}$-axons. 

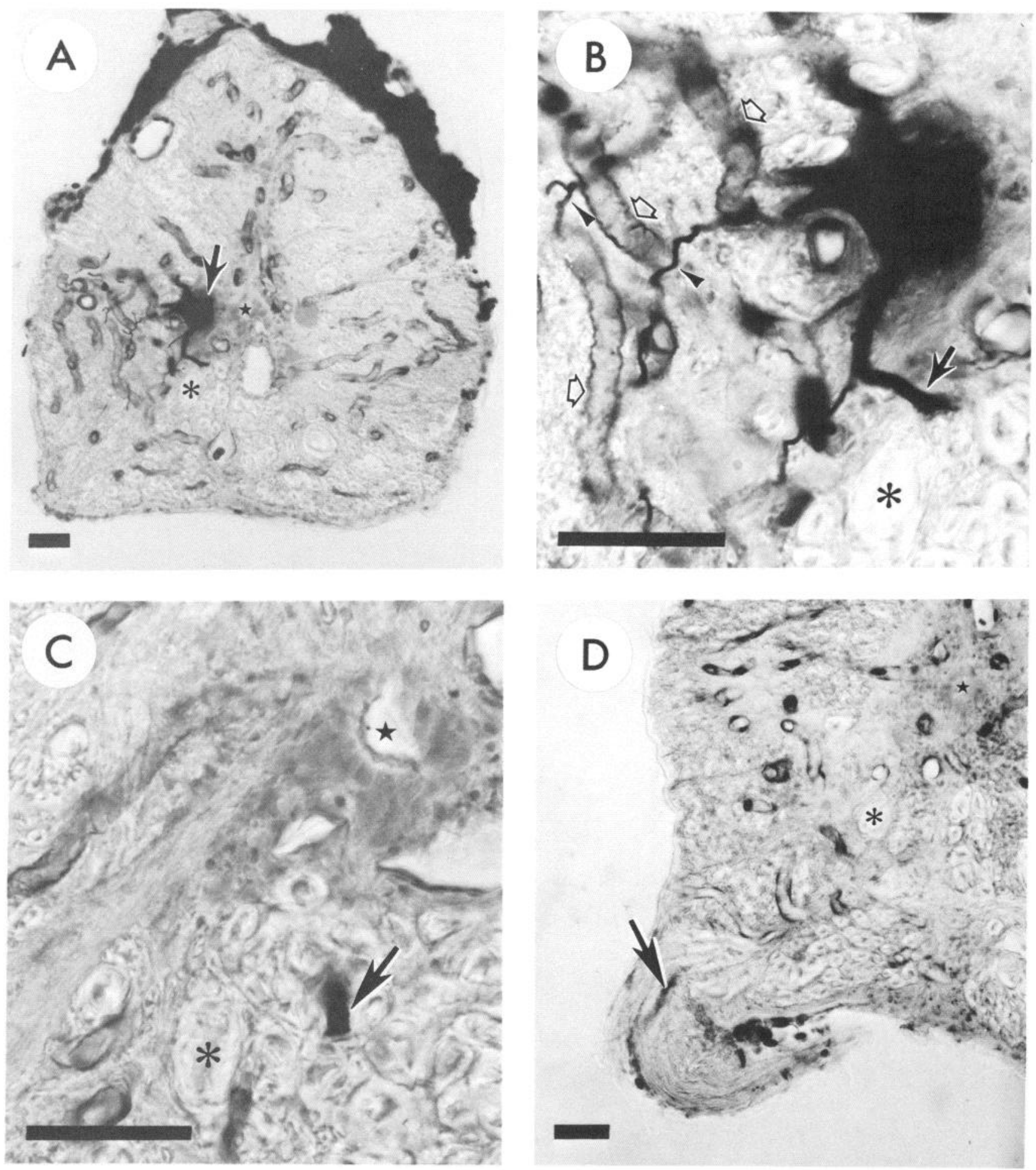

Figure 2. Morphology of a motoneuron that received monosynaptic input from the ipsilateral M-axon. A, Cross section of the spinal cord showing the position of an HRP-filled motoneuron (arrow) relative to the M-axon (asterisk) that excited it and the central canal (star). B, Higher-power view of the motoneuron in $A$; its ventral process, which gives rise to the axon, is indicated by a solid arrow. Open arrows mark some blood vessels. Solid arrowheads indicate dendrites of the motoneuron. Asterisk marks the M-axon. $C$ and $D$, Position of the motor axon (arrow) of this cell in cross sections caudal to the one in $A$. The axon travels medial to the M-axon in $C$ and into the ventral root in $D$. Star marks the central canal; asterisk marks the M-axon in both $C$ and $D$. Scale, $50 \mu \mathrm{m}$. The physiology from this cell is shown in Figure 5.

In some animals, motoneurons innervating axial musculature were backfilled 6-7 d prior to an intracellular experiment by applying small pledgets of Gelfoam soaked in $30-50 \%$ HRP to axial musculature or nerves on the tail as described previously (Fetcho, 1986).

Histology. One to five hours after filling a neuron with HRP, the fish was intracardially perfused, first with fish saline $(124 \mathrm{~mm} \mathrm{NaCl}, 5.1 \mathrm{~mm}$ $\mathrm{KCl}, 3.0 \mathrm{~mm} \mathrm{NaH}_{2} \mathrm{PO}_{4} \mathrm{H}_{2} \mathrm{O}, 0.9 \mathrm{~mm} \mathrm{MgSO}_{4} 7 \mathrm{H}_{2} \mathrm{O}, 5.6 \mathrm{~mm}$ glucose, $1.6 \mathrm{~mm} \mathrm{CaCl}_{2} 2 \mathrm{H}_{2} \mathrm{O}, 20 \mathrm{~mm}$ HEPES, taken to $\mathrm{pH} 7.2$ with Tris), and then with $5 \%$ glutaraldehyde in phosphate buffer $(0.2 \mathrm{M}, \mathrm{pH} 7.4)$. Several segments of the spinal cord in the region containing a labeled cell were 
completely exposed and fixed in situ overnight in glutaraldehyde. The spinal cord was then removed, fixed for at least another $2 \mathrm{hr}$, and placed in a solution of $30 \%$ sucrose in phosphate buffer overnight. The cords wcrc cmbedded in a block of gclatin that was trimmed, fixcd in phosphate-buffered glutaraldehyde with $30 \%$ sucrose, frozen, and serially sectioned-usually at $40 \mu \mathrm{m}$ in the transverse plane, occasionally at from 40 to $200 \mu \mathrm{m}$ in the horizontal or sagittal planes. Sections were mounted on gelatin-subbed slides.

All sections were treated for peroxidase by using a modification of the cobalt intensification of the diaminobenzidine (DAB) reaction (Adams, 1977). Sections were counterstained in cresyl violet $(0.5 \%$ in acetate buffer, $\mathrm{pH}$ 5.0), dehydrated in alcohols, cleared in Histosol, and mounted under a coverslip in permount or Cytoseal (Stephens Scientific, Oak Ridge, NJ).

Neuronal morphology was examined in the serial sections, and in some cases neurons were reconstructed from camera lucida tracings of the sections. The cross-sectional areas of neurons were measured at 920 or 1900 times by tracing the outline of their somata on a digitizing tablet interfaced with an Apple IIE computer.

\section{Results}

\section{General remarks}

We found 3 classes of neurons that received short-latency input from the M-axons. Two were chemically excited by the ipsilateral M-axon, and the third was electronically coupled to it. All 3 classes were inhibited by the contralateral M-axon. The physiology and morphology of the cells are dealt with below. For the chemically excited cells we only consider the physiology from neurons that were also successfully identified morphologically. However, similar physiological data were obtained from many more neurons that are not included because, for one reason or another, they were not successfully filled with HRP for conclusive identification.

\section{Primary motoneurons}

\section{Morphology}

The members of the first class of neurons ( $n=19$ successful fills) that received short-latency, chemical excitatory input from the ipsilateral $\mathrm{M}$-axon were identified as motoneurons by tracing their axons into ventral roots in serial sections. All but one of these motoneurons were morphologically similar to the one shown in Figure 2. Their relatively large cell bodies (arrow in Fig. $2 \mathrm{~A}$ ) were located in the dorsal portion of the axial motor column, whose boundaries were defined in an earlier work (Fetcho, 1986). Dendrites arising from the soma extended mainly laterally, where they branched to run rostrally and caudally in the cord. A major process, labeled by the solid arrow in Figure $2 B$, arose from the soma, ran ventrally, turned toward the $\mathrm{M}$-axon, looped around its medial side (as in Fig. 2C), and continued caudally and ventrally as the axon that entered the ventral root (Fig. 2D). No processes of these neurons crossed to the contralateral side of the cord.

The large size of these cells relative to other neurons in the motor column is shown in Figure 3, which presents, for 5 separate experiments, the size distributions of cells found in the motor column in the same region of the cord as the filled one. The bin occupied by the labeled motoneuron is marked with an arrow on each histogram. The distribution of neurons in the motor column was skewed toward the larger size classes like the distribution of motoneurons backfilled with HRP applied to axial muscle (Fetcho, 1986). The motoneurons that received short-latency input from the M-axon occupied the upper tail of the distribution, indicating that they were among the largest motoneurons in the motor column.

The ventral process of these motoneurons always approached

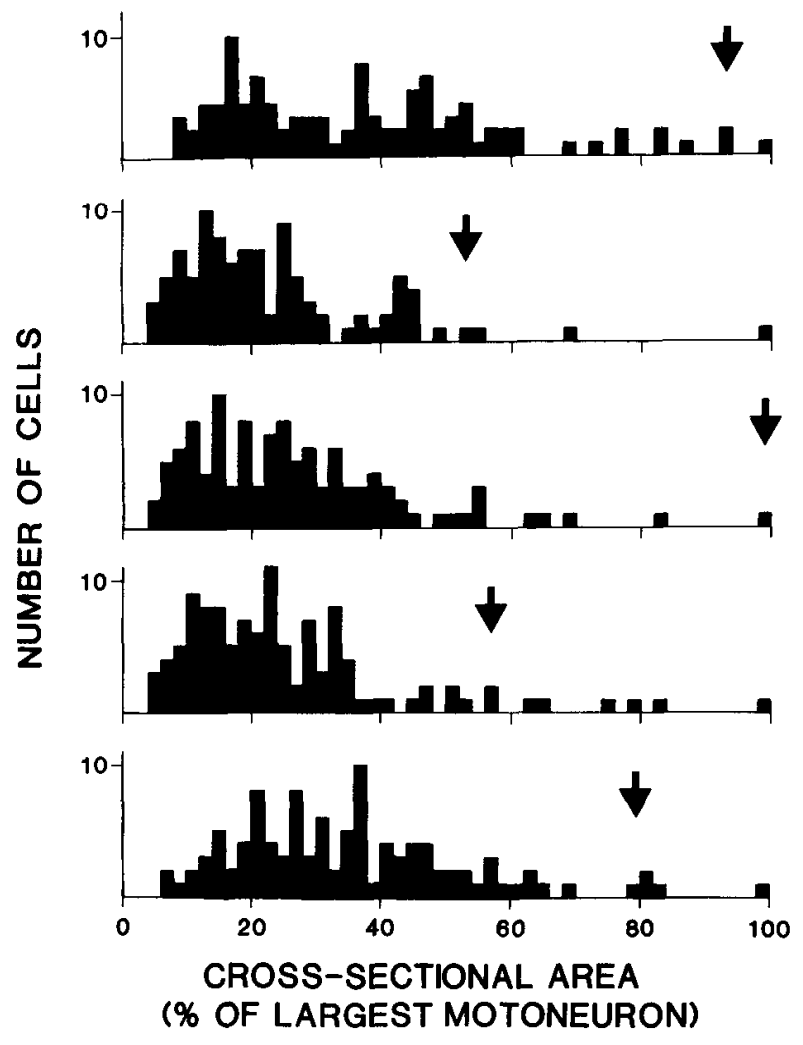

Figure 3. Size distributions of neurons in the motor column from 5 different experiments in which single motoneurons that were monosynaptically excited by the M-axon were filled with HRP. The arrow in each histogram marks the bin occupied by the monosynaptically excited motoneuron, which in all cases is among the largest $1-10 \%$ of neurons in the motor column. These histograms were produced by measuring the size of roughly 100 nerve cells in the motor column on both sides of the cord in several sections, including, and adjacent to, the one containing the HRP-filled cell. The cross-sectional areas of all neurons in each section were measured until a total of about 100 cells was reached.

the M-axon and was sometimes closely apposed to it. To evaluate the relationship between these cells and the M-axon, we filled both the M-axon and individual motoneurons excited by it in the same segment of the spinal cord with HRP. The morphology of the M-axon in the caudal spinal cord was similar to its morphology in rostral cord (Yasargil et al., 1982; Funch et al., 1984). It ran longitudinally in the median longitudinal fasciculus (MLF), and small collaterals arose from its dorsal or dorsolateral side at intervals of roughly $240 \mu \mathrm{m}$ [mean $=237$, $\mathrm{SD}=90$; sample size, $n=27$; in one $10.8 \mathrm{~cm}$ fish, the spacing in other fish in the range of sizes used in this study also averaged a few hundred microns]. These collaterals extended an average of only $24 \mu \mathrm{m}$ from the M-axon (SD $=6 ; n=29$ ); no processes from the M-axon crossed the spinal cord. In paired motoneuron/ M-axon fills, like the one shown in Figure 4, a collateral of the $\mathrm{M}$-axon was closely apposed to the ventral process of the motoneuron it excited, with no space between the 2 visible at the light microscopic level.

Based on their large size, dorsal location, and the medial trajectory of their axons relative to the M-axon, these motoneurons are the primary motoneurons identified in an earlier study (Fetcho, 1986), which showed that they innervate exclusively the faster white muscle fiber types in the myomeres of goldfish. The only motoneuron that received a short-latency 

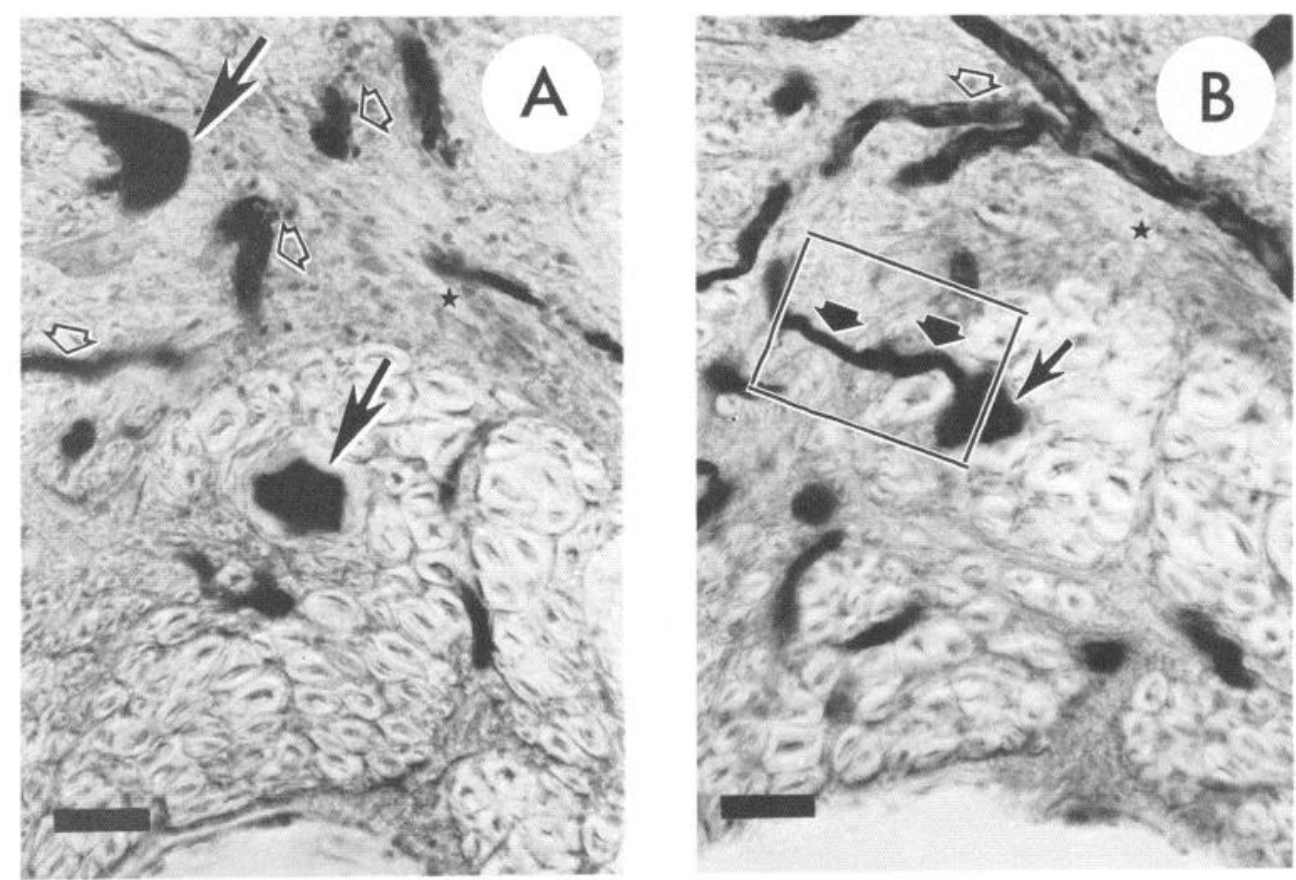

Figure 4. An anatomical connection between a $\mathrm{M}$-axon and a motoneuron monosynaptically excited by it. $A$, Cross section showing the location of an HRPfilled cell body of a motoneuron (upper solid arrow) and the HRP-filled M-axon (lower solid arrow) that monosynaptically excited it. $B$, Cross section caudal to the one in $A$, showing a ventral process from the motoneuron (solid arrow at left in boxed area) contacted by a $\mathrm{M}$-axon collateral (solid arrow at right in boxed area). Solid arrow outside boxed area points to the M-axon. Open arrows in $A$ and $B$ mark blood vessels; stars mark the central canal. $C$, Higher-power view of the boxed region in $B$. Arrows mark, from left to right, the ventral process of the motoneuron, the location of the contact between the collateral of the $\mathrm{M}$-axon and the motoneuron, and the M-axon collateral. Scale bars, $30 \mu \mathrm{m}$.

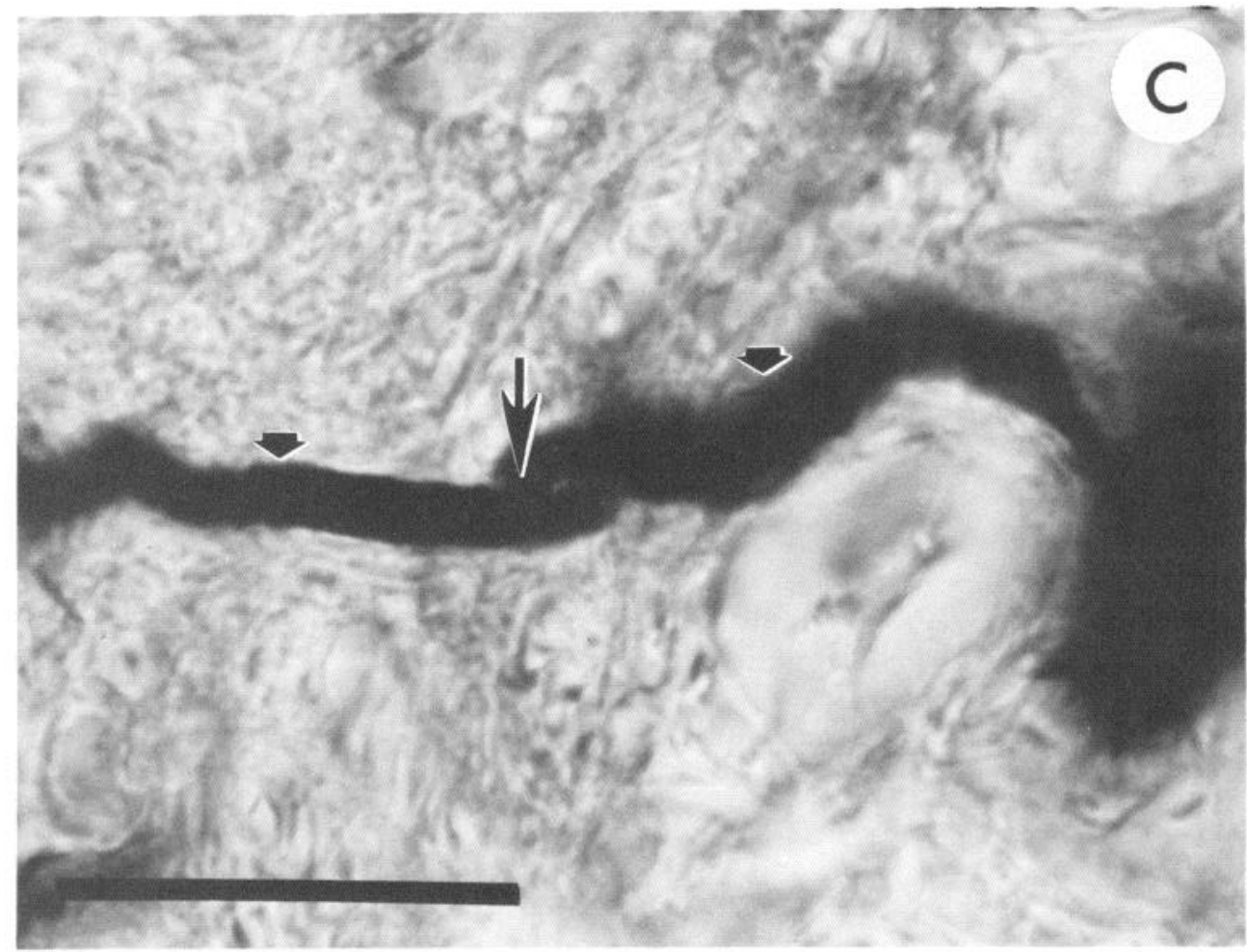

input from the M-axon but did not show the typical morphological characteristics of primary motoneurons was a cell with a relatively large, unipolar soma and a small axon that ran lateral to the M-axon along its way to the ventral root.

The observation that motoneurons excited at short latency by the M-axon were almost exclusively the largest ones was not simply a consequence of an inability to record from smaller motoneurons that might also have been excited at short latency. In a few cases in which we filled cells that were antidromically activated from the ventral root or excited at longer latency by one of the M-axons, the filled cells were smaller motoneurons. Therefore, we infer that our electrodes sampled the much more numerous, smaller, secondary motoneurons but that these cells usually did not receive the shortest latency input from the M-axon.

\section{Physiology}

The physiology from 2 primary motoneurons is shown in Figure 5. Panels A1 and A2 illustrate the physiology from the cell whose morphology is shown in Figure 2. A spike in the M-axon ipsi- 

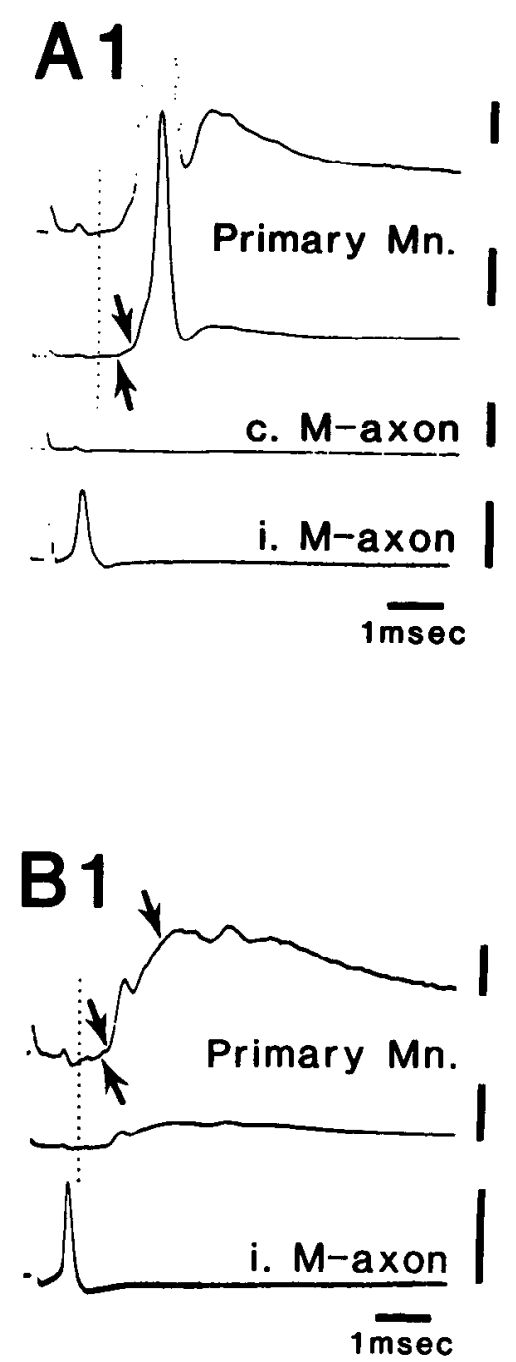

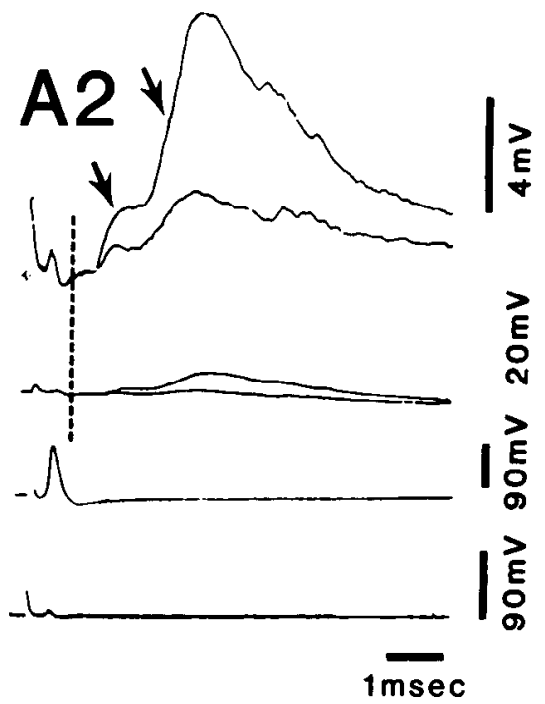

B2

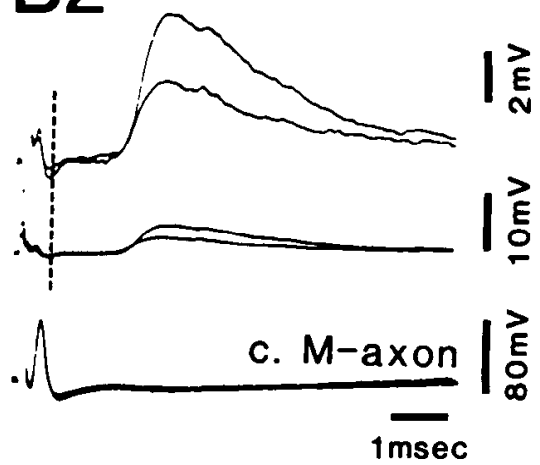

Figure 5. Electrophysiology from 2 primary motoneurons. $A 1$ and $A 2$, Intraccllular recordings from the samc primary motoneuron. Two upper traces in $A l$ show low- and high-gain records of an EPSP and spike in the primary motoneuron in response to a spike in the ipsilateral ( $i$ ) M-axon (bottom trace). The dotted line marks the arrival of the $\mathrm{M}$-axon spike in the spinal segment containing the primary motoneuron. Arrows mark the beginnings of 2 components of the EPSP including, from left to right, an initial small depolarization, followed by a more rapid depolarization that gave rise to the action potential. A2, The inverted IPSP ( 2 upper traces) that occurred in response to firing the contralateral (c) M-axon (second trace from bottom). The IPSP had early and late components (arrows; see text). The 2 superimposed responses on the top trace were obtained before (smaller depolarization) and after (larger depolarization) passing additional hyperpolarizing current to further load the cell with chloride and change the chloride equilibrium potential. Thus, they demonstrate the chloride dependence of the IPSP. Dashed line marks the arrival of the $M$-axon spike in the spinal segment. Note that the latency of this connection, measured as the distance between the dashed line and the beginning of the IPSP, was only slightly longer than that of the EPSP in $A 1 . B 1$ and $B 2$, The EPSP $(B 1)$ and inverted IPSP $(B 2)$ in another primary motoneuron that did not produce an action potential in response to firing the ipsilateral M-axon. In $B 1$, the beginnings of the different components of the EPSP that probably correspond with those marked in $A 1$ are indicated by the first 2 arrows at left. Note the late long depolarization (right-most arrow), similar to the depolarization that follows the action potential in $A 1$. Unlike the cell in $A 1$ and $A 2$, the latency of the IPSP unmasked in this cell by successive $\mathrm{Cl}^{-}$injections (B2) was considerably longer than the latency of the EPSP (see text for further discussion).

lateral to these motoneurons resulted in a short-latency, excitatory postsynaptic potential that is suprathreshold in one of these cells (A1) and subthreshold in the other (B1). The synaptic latency at this connection was short and constant in each cell; the mean latency was $0.49 \mathrm{msec}$ in 12 primary motoneurons $(\mathrm{SD}=0.16 \mathrm{msec})$. The EPSPs were reduced in amplitude and eventually eliminated as the frequency of stimulation of the $\mathrm{M}$-axon was increased from roughly 0.3 to $10 \mathrm{~Hz}$. This, in conjunction with the roughly $0.5 \mathrm{msec}$ synaptic delay, indicates that the connection is a fatigable, chemical synapse.

In many cases the EPSP did not lead to a spike in the mo- toneuron, even though intracellular current injections demonstrated that the neurons were capable of generating action potentials. The subthreshold EPSPs typically consisted of 3 components as shown in Figure 5, panel B1. An initial small depolarization was followed by a fast depolarization that, in turn, was followed by a long, slower depolarization. The primary motoneurons that did produce action potentials in response to firing the M-axon only produced a single action potential for each one in the M-axon. The first 2 components of the EPSPs are also seen in these neurons, as shown in Al, where their beginnings are marked by arrows. The spike in this cell was 
followed by a long depolarization, which may correspond to the late component seen in the subthreshold EPSPs.

The primary motoneurons received a chloride-dependent inhibition from the contralateral $\mathrm{M}$-axon. Usually, immediately after penetrating one of these neurons with a $\mathrm{KCl}$ electrode, firing the contralateral $\mathbf{M}$-axon produced either no obvious change in membrane potential or a slight hyperpolarization (not shown). Within several seconds to a minute, the hyperpolarization was inverted to a small depolarization, presumably because of leakage of $\mathrm{Cl}^{-}$from the electrode into the neuron. This depolarization was increased substantially by loading the cell with $\mathrm{Cl}^{-}$by passing hyperpolarizing current into it (Fig. 5, A2, B2), indicating that the potential is indeed chloride dependent. These inverted IPSPs lasted well over $10 \mathrm{msec}$. Their latencies varied considerably, with the mean latency in 9 cells equal to $0.94 \mathrm{msec}$ $(\mathrm{SD}=0.55 \mathrm{msec})$.

The approximate positions of our recording sites in primary motoneurons could be localized based on the position of the recording electrode relative to the $\mathrm{M}$-axon and an examination of the filled cells, which showed some disruption and a small amount of diffuse extracellular HRP reaction product near what we infer was the injection site. Recordings from primary motoneurons were most easily obtained very near the $\mathbf{M}$-axons or approximately $150 \mu \mathrm{m}$ dorsal to them. These sites correspond histologically to the ventral dendrite or initial portion of the axon and to the somatic region, respectively.

IPSPs unmasked by $\mathrm{Cl}^{-}$injections into these 2 different regions of the primary motoneurons had different latencies, and the variability in latency mentioned above was a consequence of this relationship. IPSPs had either a short latency, a long latency, or a combination of short- and long-latency components. Figure $5 A 2$ shows an IPSP that had both short- and longlatency components, which are marked by arrows. The latency of the first component is only about $0.2 \mathrm{msec}$ longer than that of the EPSP in the same cell, which is shown in Figure $5 A 1$. IPSPs recorded from the ventral process or initial portion of the axon $(n=5)$ only showed this shorter-latency component. IPSPs recorded dorsally, in the region of the soma $(n=4)$, always had the later component, which had a latency of more than a millisecond, as shown in B2. The latencies of the inverted IPSPs were related to the recording location and not to any obvious morphological differences been individual primary motoneurons with IPSPs of different latencies. We suspect that individual primary motoneurons receive inhibition from the contralateral M-axon via 2 different pathways-a short-latency one that inhibits the motoneurons ventrally near where they receive their excitatory input and a longer-latency pathway that inhibits the motoneurons dorsally in the region of the soma. When we recorded from the soma we usually inverted only the longerlatency inhibition located near the site of $\mathrm{Cl}^{-}$injection but not the shorter-latency one far from the injection site; ventral recordings, on the other hand, inverted the short-latency component but not the longer-latency one. The presence of these 2 sources of inhibition in individual primary motoneurons is supprted by observations of biphasic IPSPs in single motoneurons, like the one shown in Figure $5 A 2$, that had both shortand longer-latency components corresponding in latency to the 2 components recorded from different regions in other primary motoneurons. Additional support for the presence of 2 sources of inhibition comes from one filled primary motoneuron in which a late inhibition was revealed by chloride injection but which also had a shorter-latency, uninverted inhibition that was revealed by its ability to block the EPSP produced by firing the ipsilateral M-axon when the EPSP was timed to occur before the start of the inverted IPSP (not shown).

\section{Summary of $M$-axon/primary motoneuron connections}

The short, constant latency and fatigability of the excitatory input from the M-axon, in conjunction with the intracellular fills of motoneurons and the $\mathbf{M}$-axon, provide strong evidence that the M-axon has monosynaptic, chemical excitatory contacts onto the largest ipsilateral motoneurons. We know from earlier work (Fetcho, 1986) that these primary motoneurons innervate the faster, white muscle fiber types in the myomeres. The primary motoneurons are inhibited by the contralateral $\mathrm{M}$-axon via 2 different pathways. A short-latency pathway inhibits them ventrally where they receive their excitatory input from the ipsilateral M-axon. A longer-latency one inhibits the cells in the region of the soma. Both of these pathways must contain interneurons between the $\mathrm{M}$-axon and contralateral primary motoneurons because the intracellular fills show that neither $\mathrm{M}$-axons nor primary motoneurons have crossing processes that would allow a direct connection between the two. The short-latency inhibition is not long enough for 2 chemical synapses between the $\mathrm{M}$-axon and contralateral motoneurons, and this suggests that the interposed interneuron is electrotonically coupled to the M-axon and crosses the cord to chemically inhibit the contralateral primary motoneurons.

\section{Descending interneurons}

Morphology

The second class of neurons ( $n=23$ fills) that received shortlatency, chemical excitatory input from the ipsilateral $\mathrm{M}$-axon was formed by descending interneurons. Photomicrographs of portions of 3 of these cells are shown in Figures 6, 9, 10, and 11 , and Figure 7 shows a camera lucida reconstruction of another one. The somata of these neurons were of medium size (mean cross-sectional area $287 \mu \mathrm{m}^{2} ; \mathrm{SD}=105 \mu \mathrm{m}^{2}$; sample size, $n=$ 10) and were located dorsolateral to the central canal (Figs. 6, $10,11)$. They had sparse dendrites that usually extended a short distance laterally, as well as rostrocaudally. The major process of each cell, which is marked by the lower arrows in Figure 6, $A$ and $B$, ran ventrally and caudally to a region near the dorsal surface of the $\mathrm{M}$-axon in the vicinity of the M-axon collaterals. Paired fills of M-axons and interneurons showed collaterals that appear to contact this process of the interneuron (not shown). The ventral process continued caudally for a distance of between 2 and 3 body segments moving along the way from a ventral position like that in Figure $6 C$ to a position in the dorsolateral white matter (as shown in Fig. 6D). In caudal regions the myelination of the process was evident as a translucent "halo" (only faintly visible in Fig. 6D) surrounding an HRP-filled core. This myelination, in conjunction with the branches that arose from the process and contacted other neurons (discussed below), indicates that this descending process is an axon.

Numerous branches arose from the descending process as it ran caudally in the cord. These branches ramified extensively throughout the motor column with most caudal to the soma, although a few were usually rostral to it. As shown in the reconstruction in Figure 7, in rostral regions, where the descending process was located within the motor column, branches from it extended both dorsally and ventrally (Fig. 7, B, C). As the process descended and moved well dorsal to the motor column, branches arose only from its ventral side and extended ventrally 

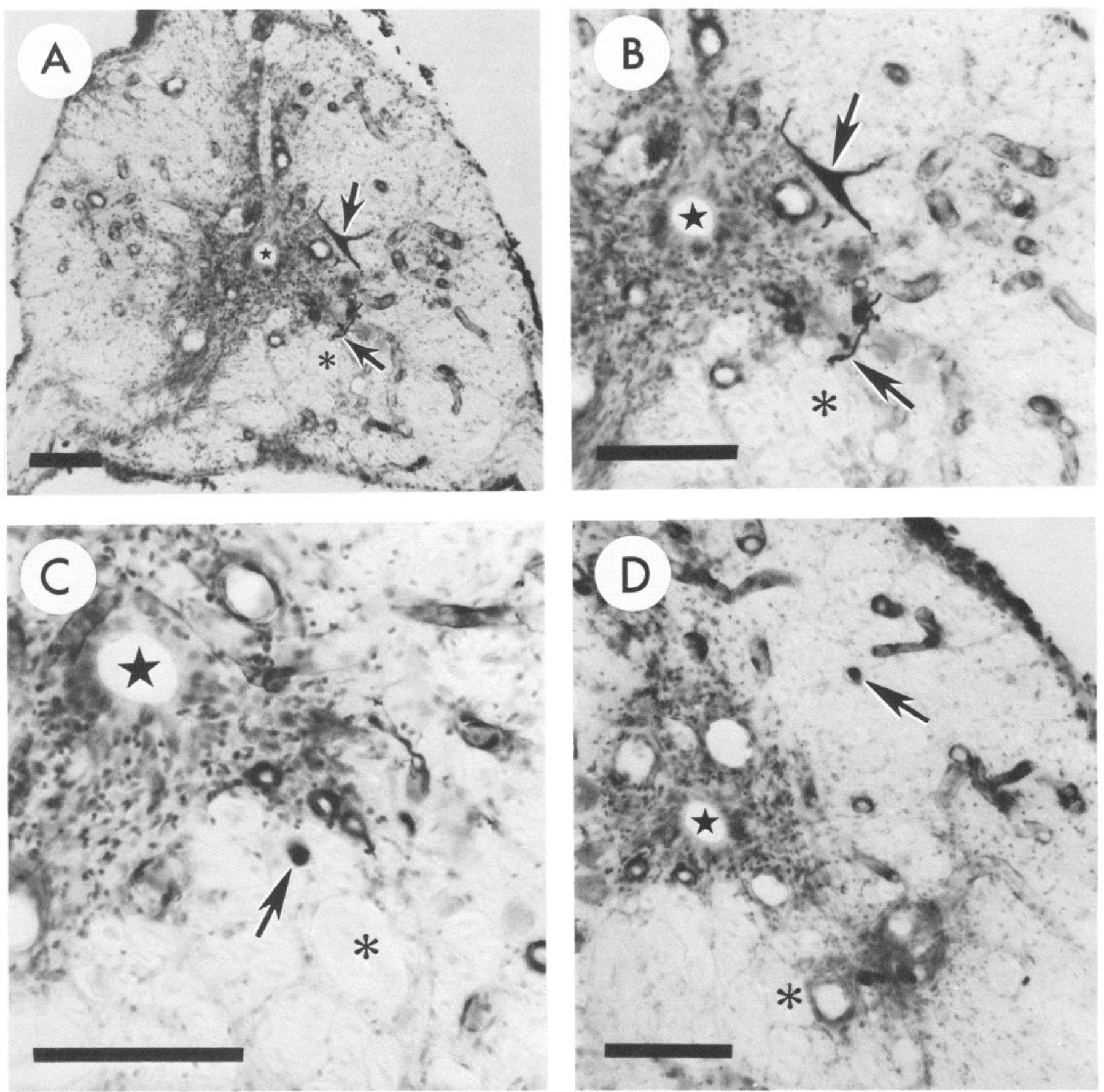

Figure 6. Morphology of a descending interneuron. A. Cross section of the spinal cord showing the cell body (upper arrow) and ventral process (lower arrow) of an interneuron that received monosynaptic input from the ipsilateral M-axon. Asterisk marks the M-axon; star, the central canal in this and the other 3 panels. $B$, Higher-power view of the cell body and ventral process shown in $A$. The portion of the ventral process of the interneuron visible in this section runs ventrally to a region very near the ipsilateral M-axon. $C$ and $D$, Sections 80 and $2280 \mu \mathrm{m}$ caudal to $A$, illustrating the caudal trajectory of the ventral process (arrows) as it runs first ventrally near the M-axon $(C)$ and then dorsolateral to the central canal $(D)$, which is marked with a star. Scale bars, $100 \mu \mathrm{m}$.

to the region of the motor column before branching further (Fig. 7A).

Figure 8 shows diagrammatically the longitudinal extent of processes of these interneurons relative to the ventral roots (marked by asterisks) and the somata (marked by S's). Branches from the interneurons usually extended over a distance of at least 2 body segments, with some neurons approaching three. These represent absolute distances of 4-6 $\mathrm{mm}$ in the fixed, de- hydrated cords. Most processes lay caudal to the somata. Although the number of branches arising from the descending process usually declined considerably in its extreme caudal region, as with the cell in Figure 7, some cells had branches from the caudal process over nearly their entire length. We suspect that the variability of the caudal branching was related to the location and quality of the HRP fill. When the injection site was rostral, HRP probably did not reach the fine branches of 


\section{A \\ B \\ C}
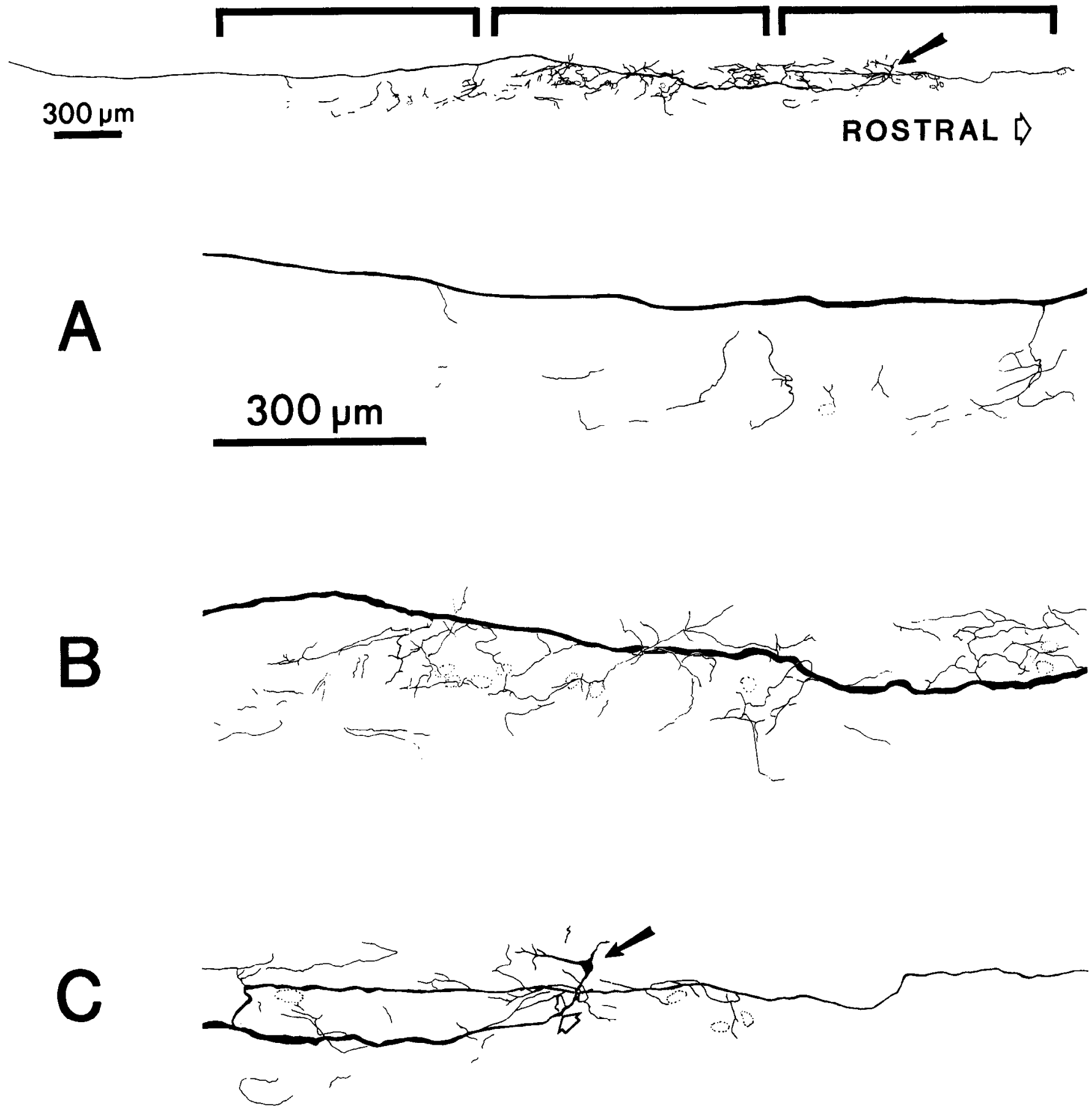

Figure 7. Reconstruction of a descending interneuron. Top panel, Complete view of the interneuron, with indicated portions shown at higher magnification in $A-C$. Rostral is to the right, and dorsal is up. Arrow marks the location of the soma, and a few neurons in the motor column are outlined by dotted lines. The main process ( $C$, open arrow) from the soma extends ventrally and caudally, where it gives rise to a recurrent collateral that extends rostrally beyond the soma. The major process then continues caudally, moving from a region within the motor column to a region dorsal to it. Branches from this process remain in the motor column throughout the processes' longitudinal course. In the region of the soma, where the descending process lies within the motor column, branches extend both dorsal and ventral to the process. As it runs caudally, and moves dorsal to the motor column, branches extend only from its ventral side.

the caudal process more than one segment away. At its extreme caudal end, the descending process usually became smaller in diameter, and the HRP staining gradually faded. Given the likelihood that the HRP did not fill the descending process beyond the 4-6 $\mathrm{mm}$ length usually observed in our preparations, the 2- to 3-segment extent of the output of these interneurons must be regarded as a lower limit.

The branches of the interneurons contacted the somata and 


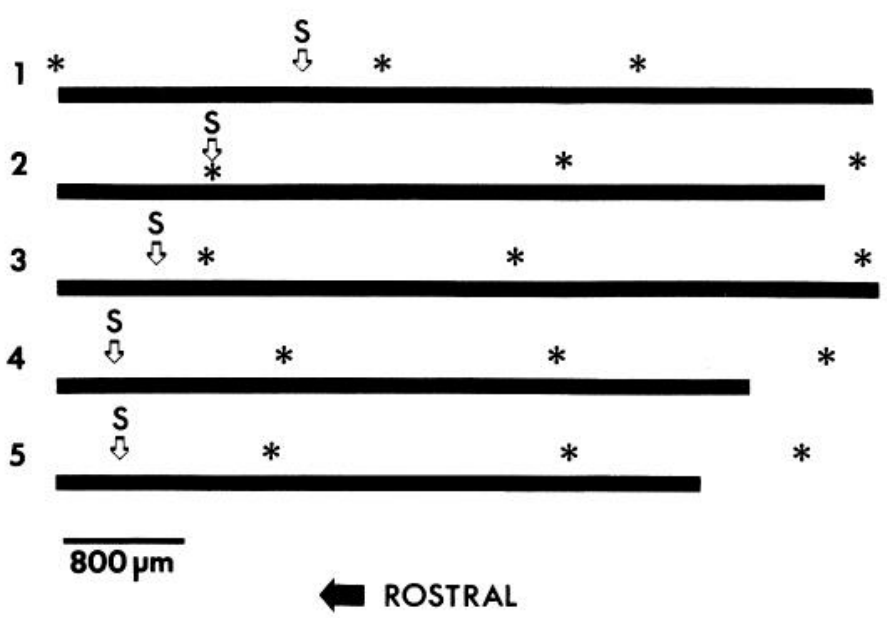

Figure 8. Diagram showing the longitudinal extent of 5 descending interneurons. Black bars indicate the length of the cord over which branches of 5 interneurons extend. The positions of their somata are marked by $S$ 's, and asterisks mark the location of ventral roots. Rostral is to the left.

dendrites of many neurons, like that shown in Figure $9 A$, that were located throughout the transverse extent of the medial motor column. Because these neurons had the morphology of motoneurons (Fetcho, 1986), these observations suggested that the interneurons had extensive contacts with axial motoneurons. To examine this, we backfilled motoneurons with HRP applied to the musculature $(n=2)$ or spinal nerves $(n=1)$ in 3 fish, and 3-4 d later recorded from and HRP-filled a descending interneuron in the same region of the cord as the backfilled motoneurons. In these fish there were many contacts at the light microscopic level between processes of interneurons and dendrites and somata of HRP-filled primary and secondary motoneurons spread throughout much of the transverse extent of the motor column (see Fig. 9B). These connections were clearest in the 2 cases in which HRP was applied to musculature because, in these, the motoneurons were only lightly filled whereas the interneuron was solid black.

\section{Physiology}

The interneurons were excited by the ipsilateral M-axon after a short, constant latency that averaged $0.5 \mathrm{msec}$ in 13 cells (SD $=0.17 \mathrm{msec}$ ). In most cells, like that shown in Figure $10 \mathrm{~A}$, stimulation of the M-axon at low frequency (roughly $0.2-0.5$ $\mathrm{Hz}$ ) produced EPSPs that reached threshold and gave rise to action potentials. Single spikes in the M-axon produced only single spikes in the interneurons. Higher-frequency stimulation (roughly $1-5 \mathrm{~Hz}$ ) revealed the EPSPs underlying the spikes (Fig. $10 \mathrm{~B}$ ), and these EPSPs were eliminated as the frequency was increased still further to between 5 and $10 \mathrm{~Hz}$. The EPSPs were relatively simple, without the several components evident in the EPSPs of motoneurons.

Like the primary motoneurons, these interneurons were inhibited by the contralateral M-axon. This inhibition is shown in Figures $10 C$ and $11 B$, where it is revealed by pairing a spike in the ipsilateral M-axon that would, by itself, give rise to a suprathreshold EPSP in the interneuron with a slightly later spike in the contralateral M-axon. In these examples, the inhibition from the contralateral M-axon truncated the EPSP (arrows in $10 C$ and $11 B$ ) in the interneuron before it reached threshold. If, as in Figure $11 \mathrm{~A}$, the interval between the $2 \mathrm{M}$-ax-
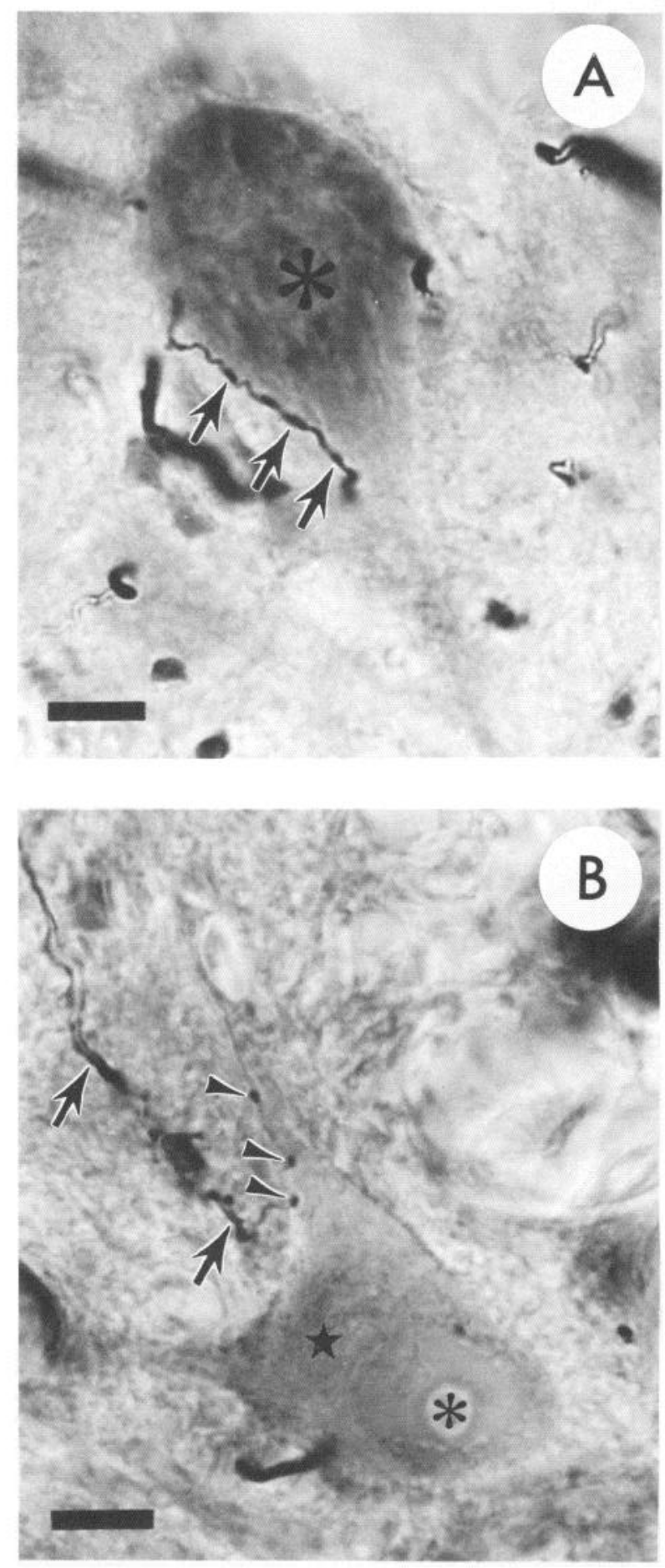

Figure 9. Contacts between processes of descending interneurons and motoneurons. A, Process from an HRP-filled interneuron (arrows) that contacts the soma of a cresyl violet-stained nerve cell in the motor column. Arrows point to swellings of the process in the region of apposition to the neuron. B, A large branch of an interneuron (arrows) that gives rise to a fine branch that forms 3 boutons (arrowheads) in contact with a dendrite of a motoneuron that was lightly backfilled with HRP applied to axial musculature. Asterisk marks the nucleolus of the motoneuron, and star marks a region of the cell somewhat darkened by the retrograde filling with HRP. Scale bars, $10 \mu \mathrm{m}$. 

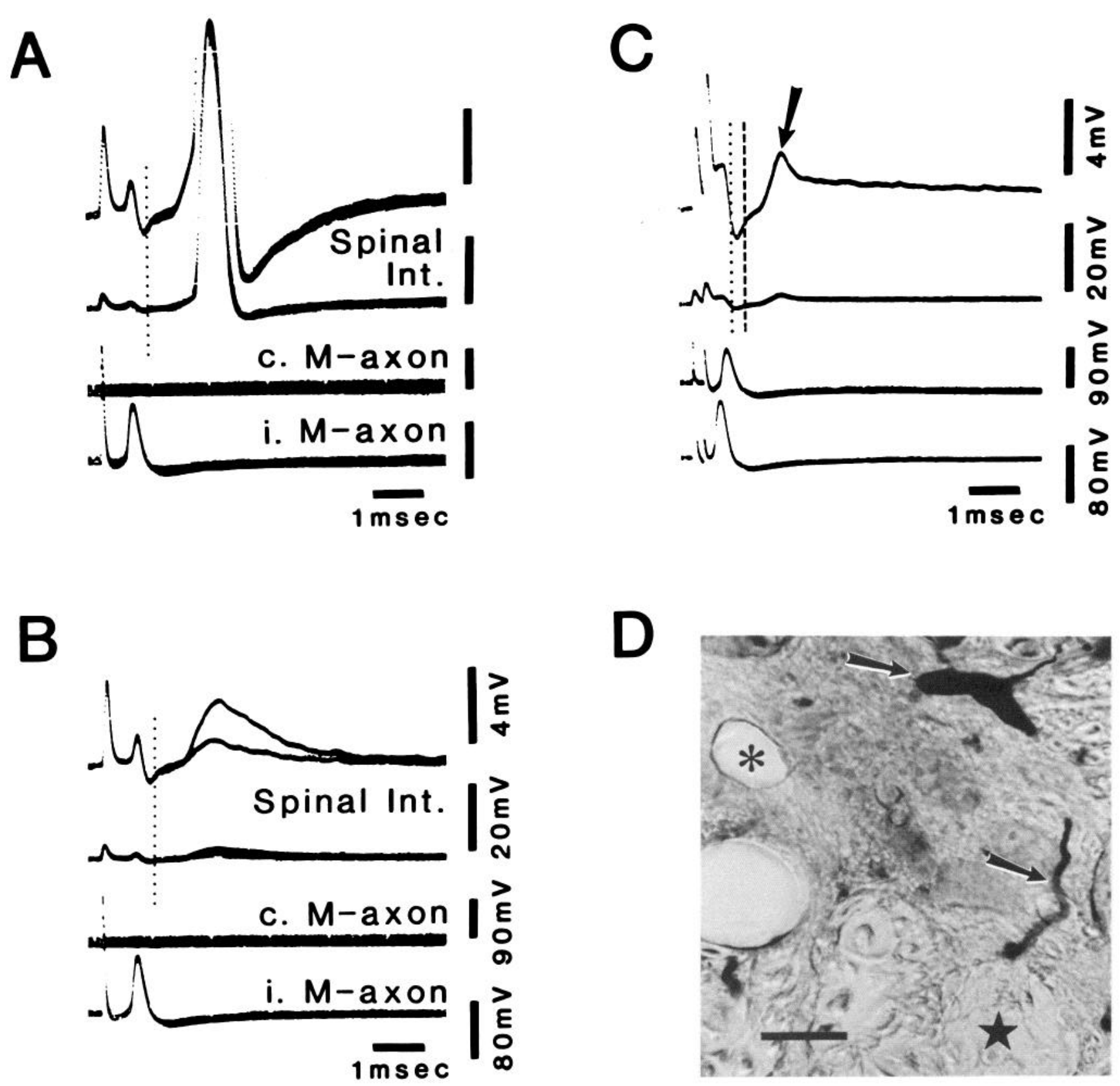

Figure 10. Physiology from a descending interneuron. Two top traces in all panels show low- and high-gain recordings from the same interneuron. The 2 bottom traces show recordings from the ipsi- and contralateral M-axons. In all panels, dotted and dashed lines mark, respectively, the arrival of the ipsi- and contralateral $\mathrm{M}$-axon spikes in the spinal segment where the recording from the interneuron was obtained. $A$, Spike in the ipsilateral $\mathrm{M}$-axon produced, after a short latency, an EPSP in the interneuron that gave rise to a spike. $B$, Higher-frequency activation (1.25 vs. $0.3 \mathrm{~Hz}$ in $A$ ) of the ipsilateral M-axon revealed the relatively simple EPSP that underlay the spike in $A$. $C$, Inhibition from the contralateral M-axon was revealed by pairing a spike in the ipsilateral M-axon that would, by itself, have produced an EPSP and action potential in the interneuron with a somewhat later spike in the contralateral M-axon. The EPSP from the ipsilateral M-axon was truncated at the arrow by the inhibition from the contralateral M-axon; this IPSP shunted the EPSP just before it reached threshold. The latency of the IPSP (distance between the dashed line and the arrow) was only slightly longer than the latency of the EPSP (distance between the dotted line and the beginning of EPSP). D, Cross section of the spinal cord containing the HRP-filled cell body (upper arrow) and ventral process (lower arrow) of this descending interneuron. Asterisk marks the central canal; star, the M-axon. Scale bar, $30 \mu \mathrm{m}$.

on spikes was increased slightly, the inhibition from the contralateral $\mathrm{M}$-axon was no longer effective because it occurred after the EPSP depolarized the cell beyond threshold. Both Figures $10 C$ and $11 B$ show that the contralateral M-axon could block an action potential in the interneuron even when the spike in this "inhibitory" M-axon occurred somewhat later than the spike in the excitatory one, as long as the inhibition became effective before the EPSP reached threshold.
The inhibition could be inverted by $\mathrm{Cl}^{-}$injection (not shown), indicating it was indeed a postsynaptic, chemical inhibition. Its latency was always short, with a mean of $0.55 \mathrm{msec}$ in 6 cells $(\mathrm{SD}=0.07 \mathrm{msec})$. In individual cells the latency of the inhibition was $0.1-0.2 \mathrm{msec}$ longer than the latency of the excitation by the other M-axon.

The last panel in both Figures 10 and 11 shows the morphology of the somata and ventral processes of the interneuron 

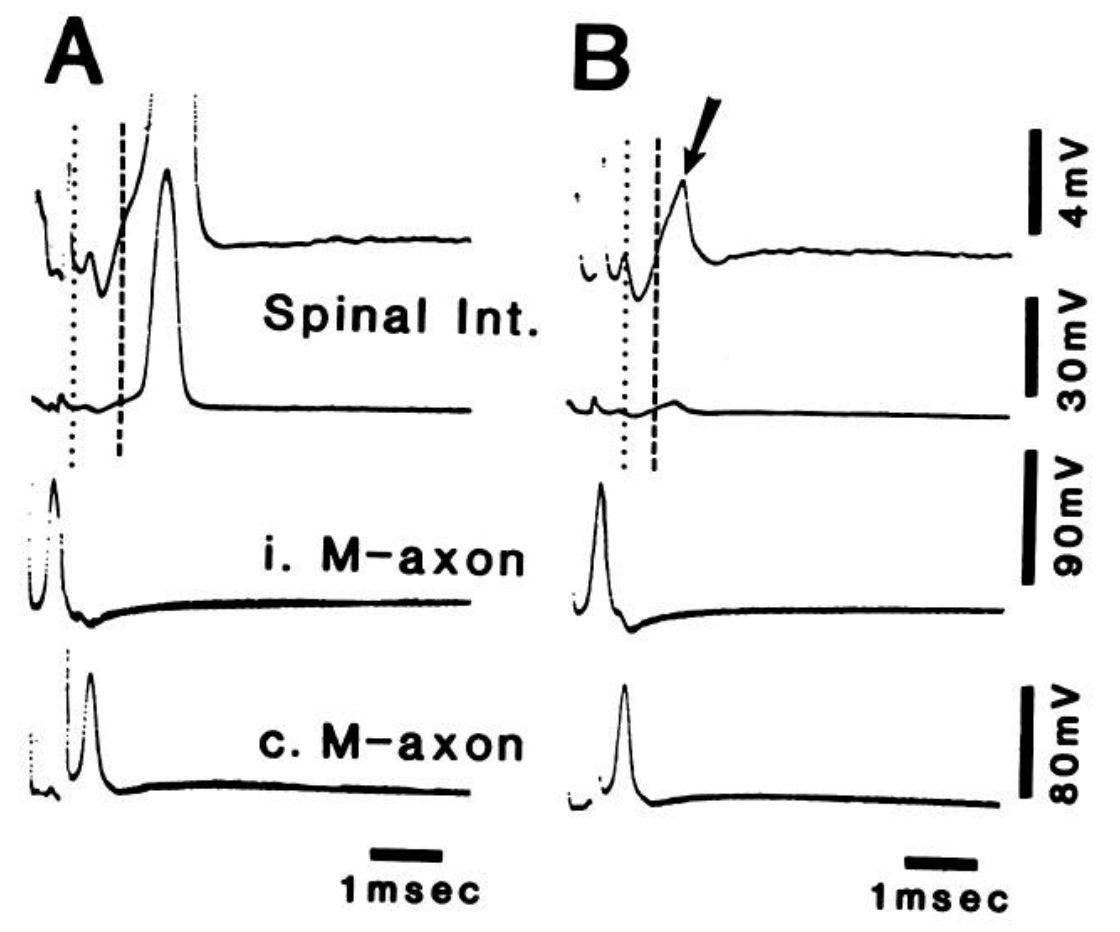

C

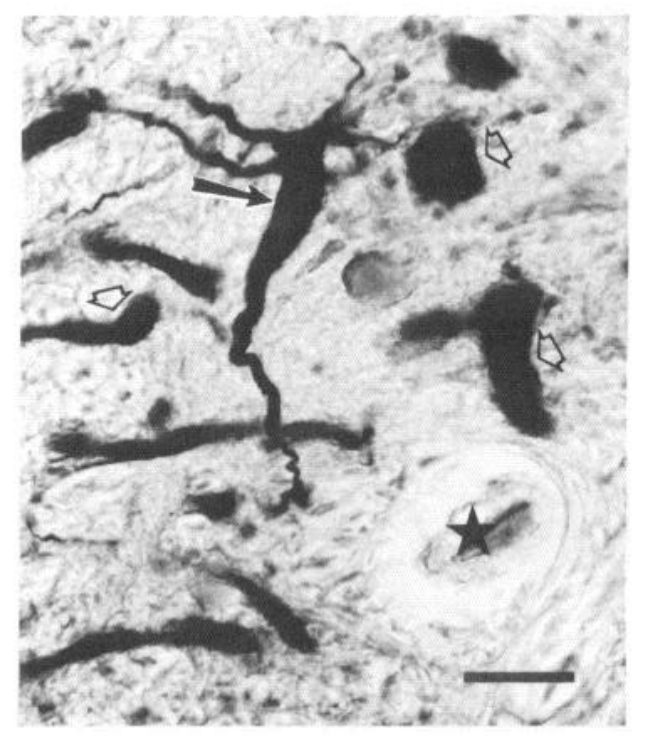

Figure 11. Intracellular recordings from a descending interneuron showing the influence of the timing of the $2 \mathrm{M}$-axon spikes on the ability of the excitatory $\mathrm{M}$-axon to produce an action potential in the interneuron. Two top traces in $A$ and $B$ show low- and high-gain recordings from the interneuron; 2 bottom traces, simultaneous recordings from ipsi- and contralateral M-axons. $A$, If the interval between spikes in the ipsi- and contralateral M-axons was long enough, the EPSP from the ipsilateral M-axon reached threshold before the inhibition became effective. $B$, With a slight decrease in the interval between them, the inhibition (arrow) truncated the EPSP and prevented the spike in the interneuron. $C$, Cross section of the spinal cord containing the cell body (arrow) of the descending interneuron whose physiology is shown in $A$ and $B$. Star marks the $\mathrm{M}$-axon; open arrows, heavily stained blood vessels. Scale bar, $30 \mu \mathrm{m}$.

whose physiology is presented in the preceding panels. In combination with Figure 6, these panels illustrate the range of variability in the morphology of the somata of these neurons.

\section{Summary of $M$-axon/descending interneuron connections}

The latency and fatigability of the excitation of the descending interneurons by the ipsilateral $\mathrm{M}$-axon, along with the close anatomical association of the two, indicate that the M-axon forms a monosynaptic, chemical synapse with these cells. In turn, the interneurons have contacts at the light microscopic level with both primary and secondary motoneurons spread throughout the transverse extent of the medial motor column over a distance of more than 2 body segments.

The interneurons are chemically inhibited by the contralateral $\mathrm{M}$-axon with a latency that is only slightly longer than the monosynaptic excitation by the ipsilateral M-axon. This short latency and the absence of crossing processes of the interneuron or the $\mathrm{M}$-axon indicate that the inhibition must be mediated by a crossing interneuron that is electrotonically coupled to the M-axon. These crossing inhibitory interneurons are perhaps the same ones that mediate the crossed inhibition of the primary motoneurons.

\section{Crossing interneurons}

Physiology

Our data from primary motoneurons and descending interneurons (see above) confirmed the prediction by Yasargil and Diamond (1968) of a class of interneurons that are electrotonically coupled to one M-axon and cross the spinal cord to inhibit neurons on the opposite side. We searched for these electroton- ically coupled cells by looking for neurons that were excited at very short latency by one of the M-axons, with a postsynaptic potential that was strongly resistant to fatigue upon high-frequency stimulation of the M-axon.

We found only one class of neurons like this, with the following physiological characteristics (some of which are shown in Fig. 12). Intracellular recordings from these cells were most easily obtained in the ventral portion of the cord in the vicinity of the M-axons. The cells received an excitatory input from the ipsilateral $\mathrm{M}$-axon at a very short latency that averaged 0.11 msec in 11 neurons $(\mathrm{SD}=0.02)$. An example of this excitation is shown in Figure $12 \mathrm{~A}$, where it fired the interneuron; the expanded sweep in Figure $12 B$ emphasizes its short latency. This excitation was extremely resistant to fatigue by high-frequency activation of the M-axon. Postsynaptic responses were evident at frequencies $>60 \mathrm{~Hz}$, which is well above the frequencies that completely eliminated the postsynaptic responses at the monosynaptic, chemical synapses onto primary motoneurons and descending interneurons. While the high-frequency stimulation could eliminate the evoked action potential, a rapid, subthreshold depolarization, which we interpret as a coupling potential, always remained (not shown). The very short latency of the response and its considerable resistance to fatigue indicate that this connection is electrotonic.

These neurons are easily confused with the M-axons in the spinal cord because of their similar location, their short-latency response to firing the $\mathrm{M}$-axon rostrally, and their fatigue resistance. However, they differed physiologically from the M-axon because firing them with current through the spinal electrode did not antidromically excite the M-axon that excited them (Fig. 

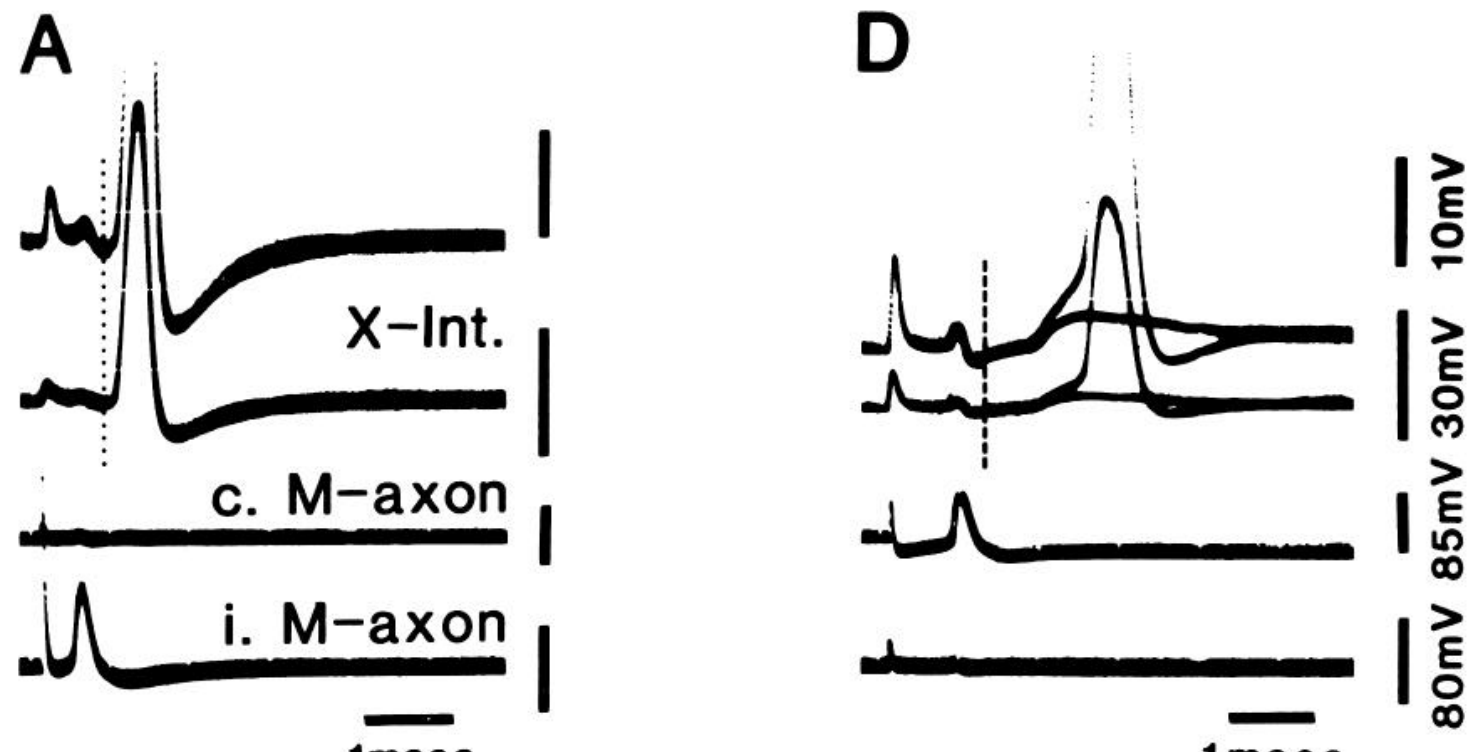

$1 \mathrm{msec}$

$1 \mathrm{msec}$
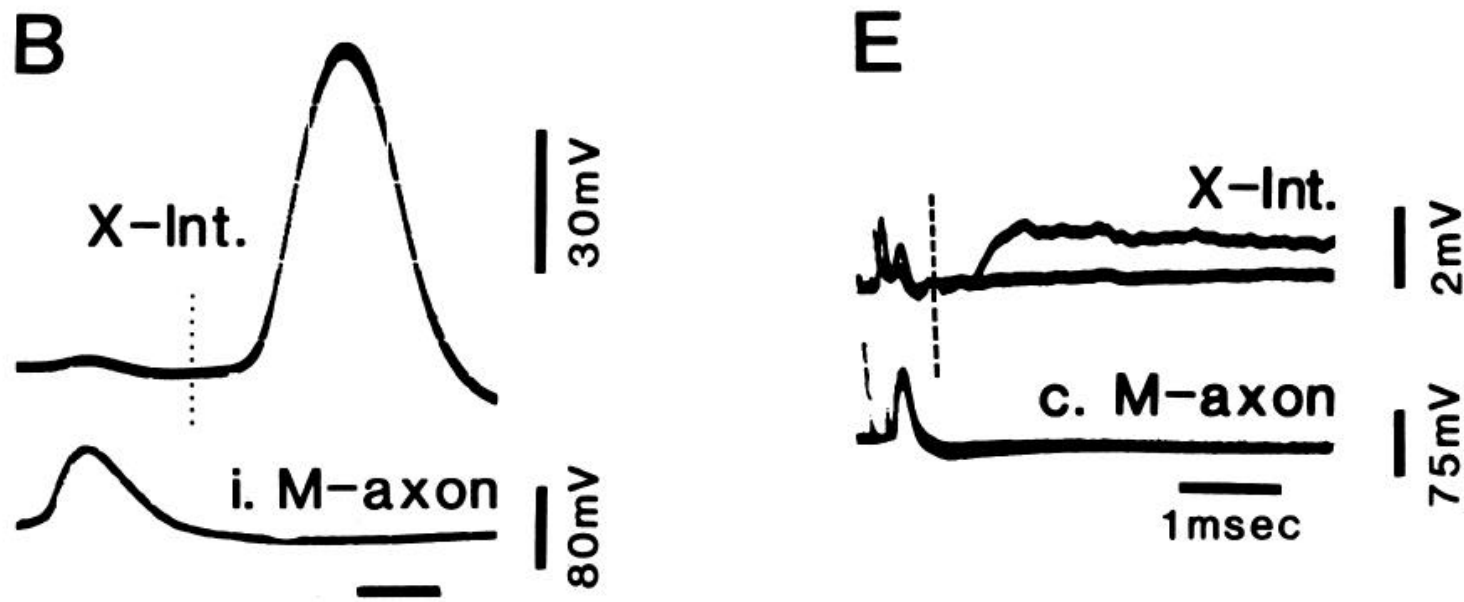

$0.2 \mathrm{msec}$

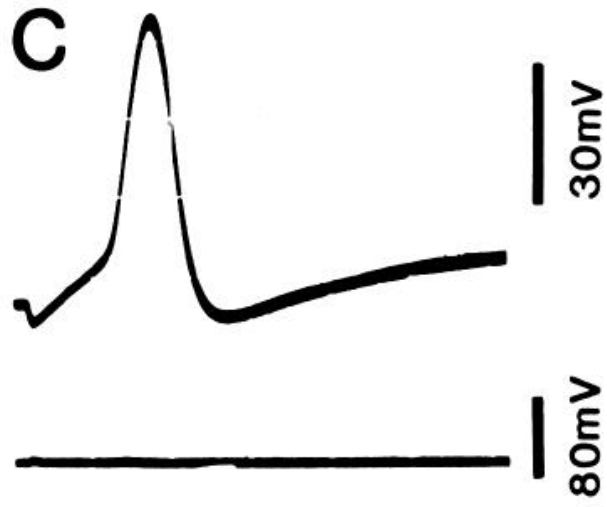

\section{$0.2 \mathrm{msec}$}

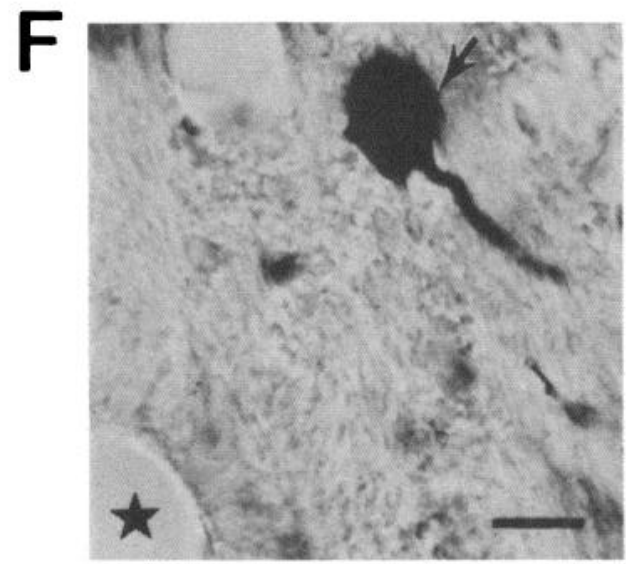

Figure 12. Crossing interneurons are electrotonically excited by the ipsilateral M-axon and inhibited by the contralateral one. $A-D$ and $F$, Physiology and morphology from the same interneuron. In $A$ and $D$, the 2 upper traces are high- and low-gain intracellular recordings from a crossing interneuron $(X$-Int.), and the 2 bottom traces are from the M-axon ipsilateral $(i)$ and contralateral $(c)$ to the soma of the interneuron. In $A$, a directly evoked action potential in the ipsilateral M-axon resulted in a very short latency $(0.12 \mathrm{msec})$ suprathreshold excitatory response in the interneuron. In $D$, firing the contralateral M-axon produced a longer-latency $(0.76 \mathrm{msec})$ IPSP that had been inverted by $\mathrm{Cl}^{-}$injection into the cell. In 1 of the 2 
$12 C$ - somcthing that was always truc of the $\mathrm{M}$-axons identified by HRP labeling in other experiments.

We recorded from these interneurons at 1 of 2 locationseither adjacent to the $\mathrm{M}$-axon that was electrotonically coupled to them or adjacent to the other M-axon. During recordings near the coupled M-axon, firing the other M-axon produced a chloride-dependent postsynaptic potential that we interpret as an IPSP; these IPSPs were not evident when we recorded from sites near the M-axon contralateral to the excitatory one. This suggests that the inhibitory input is located near the excitatory input from the electrotonically coupled $\mathrm{M}$-axon.

Examples of the IPSPs that were inverted by loading the cell with chloride are shown in Figure 12, $D$ and $E$. In Figure $12 D$ the depolarizing IPSP actually fired the interneuron, which is the same cell whose responses to the ipsilateral $\mathrm{M}$-axon are shown in panels $A$ and $B$. Generally, these neurons had no obvious response to stimulation of the contralateral M-axon immediately after penetration with the electrode, but the IPSPs could be exposed by loading the cells with chloride ions, either by pressure injection or by passing hyperpolarizing current through the $\mathrm{KCl}$ recording electrodes. With further injections, the size of these postsynaptic potentials was increased substantially. The superimposed traces in Figure 12E, which are from a different cell than the one in $A-D$, illustrate the ability of such an injection to unmask these IPSPs. The latency of these IPSPs averaged $0.56 \mathrm{msec}$ in 4 cells in which they could be revealed $(\mathrm{SD}=0.16)$. Thus, these cells are electrotonically excited by one $\mathrm{M}$-axon and inhibited by the other.

\section{Morphology}

We successfully filled 5 of these interneurons with HRP. All of them had the same gross morphology; photomicrographs of portions of 3 of them are shown in Figures 12-14, and Figure 15 shows a camera lucida reconstruction of another one. Their extremely simple, small (cross-sectional area, mean $=163 \mu \mathrm{m}^{2}$, $\mathrm{SD}=42, n=5$ ), round to oval cell bodies (solid arrows in Figs. $12 F, 13 A, 15)$ were located above and slightly lateral to the central canal on the same side of the cord as the M-axon that electrotonically excited them. The cell bodies typically had only one thin process (Fig. 13A, lower arrow), that ran ventrally from the soma to a position just dorsal to the ipsilateral $\mathrm{M}$-axon, where it enlarged substantially, passed dorsal to the M-axon (as in Fig. 13B, open arrow), and crossed the spinal cord between the $2 \mathrm{M}$-axons (like the process in Fig. $13 \mathrm{C}$, arrows). In every case the ventral process passed close enough to the ipsilateral $\mathrm{M}$-axon to receive a contact from one of its collaterals, and in the 2 cases in which both an interneuron and the M-axon that excited it were filled with HRP, a collateral of the M-axon was apposed to the ventral process of the interneuron (Fig. 13B). The ventral process of the interneuron developed myelination, visible as a clear halo in the light microscope, in the region where it crossed the midline of the cord. Once on the opposite side of the cord the crossing process sent myelinated longitudinal branches that ran rostrally and, over a longer extent, caudally, parallel and medial or dorsomedial to the contralateral M-axon. As they ran longitudinally, the processes gave rise to branches that terminated near collaterals of the $\mathrm{M}$-axon. The relationship between branches of the interneuron and the collaterals of the contralateral M-axon was striking in cross sections from the 3 experiments in which both had been filled with HRP; nearly every $\mathrm{M}$-axon collateral along the longitudinal course of the interneuron was met by a branch or branches of the longitudinal process. Examples of a few of these associations are shown in Figures 13, $D-F$, and 14. The processes of the interneurons frequently ended as a cluster of boutons (some of which are marked by arrowheads in Figs. $13 F$ and $14 A$ ). Although these endings were very near collaterals of the $\mathrm{M}$-axon, most of them clearly did not terminate on the collateral but ended just distal or medial to its tip. Only a few boutons were closely apposed to tips of collaterals. The longitudinal processes of the interneurons extended a distance of roughly one body segment (about $1.5-3 \mathrm{~mm}$ ), with branches associated with as many as $10 \mathrm{M}$-axon collaterals along the way. The reconstruction in Figure 15 shows the regular spacing of these branches, which are separated at intervals in the range of the typical $200-300 \mu \mathrm{m}$ spacing between collaterals.

The terminals of the crossing interneurons were located in regions where they could contact the ventral processes of primary motoneurons and descending interneurons close to the site where these cells receive their excitatory input from collaterals of the M-axon. The relationship between the crossing interneurons, motoneurons, and descending interneurons was confirmed in one fish in which we backfilled motoneurons with HRP applied to trunk musculature and subsequently recorded from, and HRP-filled, both a descending interneuron on the same side as the backfilled motoneurons and a crossing interneuron on the opposite side. In this fish, the crossed processes of the interneuron were closely apposed to the ventral processes of both the primary motoneurons and the descending interneuron in the region where they were contacted by collaterals of the M-axon that excited them. Some of these terminals are drawn in Figure $14 B$ in a section where they are apposed to a portion of the ventral process of a primary motoneuron.

In summary, these interneurons are electrotonically excited by the ipsilateral M-axon and chemically inhibited by the contralateral one. Their axons cross the spinal cord and terminate in a striking association with collaterals of the contralateral M-axon, where they are apposed to neurons postsynaptic to the collaterals.

\section{Discussion}

One of the most obvious and essential motor behaviors among fish and amphibians in the C-start used for escape from predators. This abrupt, powerful bend of the body and tail swivels

superimposed sweeps, this depolarizing IPSP reached threshold and produced a spike in the interneuron. Calibration bars in $D$ also apply to $A$. In $B$, the response of the interneuron (upper trace) to firing the ipsilateral $\mathbf{M}$-axon (lower trace) is shown at a higher sweep speed than in $A$ to illustrate better the short latency of the response. $C$ shows that firing the interneuron (upper trace) with depolarizing current through the intracellular electrode did not activate the ipsilateral M-axon (lower trace). $E$ shows data from another experiment demonstrating the chloride dependence of the response of crossed interneurons to firing the contralateral M-axon. The superimposed sweeps were obtained before (flat trace) and after $\mathrm{Cl}^{-}$injection. Firing the contralateral M-axon only produced a clear potential change in the interneuron after the injection. The latency of the depolarizing IPSP was $0.44 \mathrm{msec}$. $F$, Photomicrograph of the cell body (arrow) and part of the ventral process of the interneuron whose physiology is shown in $A-D$. Dotted or dashed lines in panels $A, B, D$, and $E$ mark, respectively, the arrival of the ipsi- or contralateral M-axon spikes in the spinal segment containing the interneuron. Star marks the central canal in $F$. Scale bar, $10 \mu \mathrm{m}$ in $F$. 

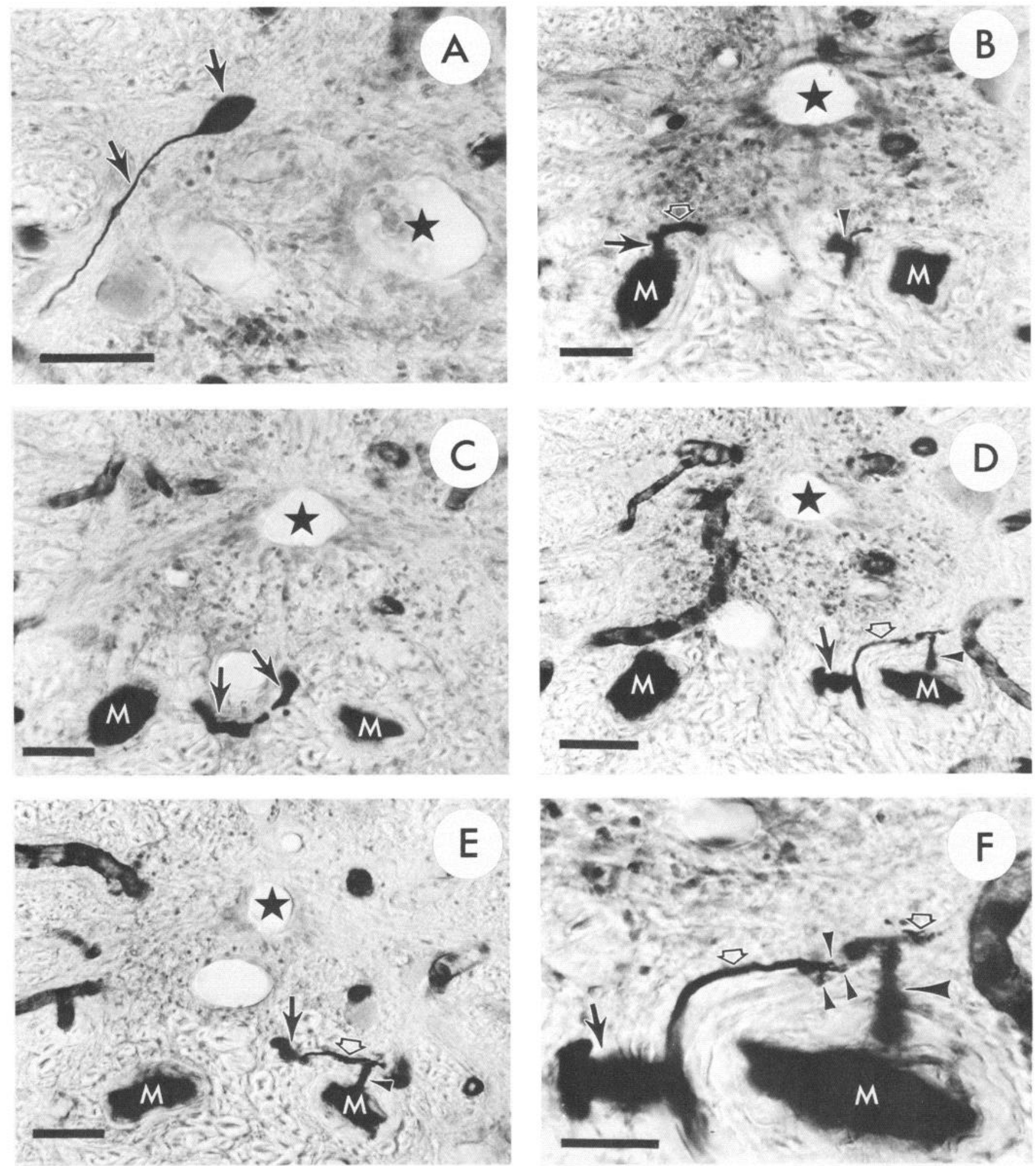

Figure 13. Morphology of a crossing interneuron that was electrotonically excited by the left M-axon. All panels show cross sections of the spinal cord with a star in the central canal and $M$ 's marking the M-axons. Successive panels trace the process of the interneuron as it crosses to the opposite side of the cord. A. The oval, dendrite-free cell body (upper arrow) that gives rise to a relatively fine process (lower arrow) which runs ventrally. $B$, Region where the ventral process of the interneuron (open arrow) is contacted by a collateral (solid arrow) of the ipsilateral M-axon. Arrowhead marks a branch of the interneurons' axon on the opposite side of the cord. The much enlarged axon of the interneuron (solid arrows) is shown in $C$ in the region where it crosses the midline after passing dorsal to the left $\mathrm{M}$-axon. After crossing the cord, this axon sends branches (solid arrows in $D$ and $E$ ) that run parallel to the contralateral M-axon. Branches arising from these longitudinal processes terminate near the distal ends of collaterals. Two examples of these branches are marked by open arrows in $D$ and $E$ along their course toward a contralateral M-axon collateral (arrowhead). $F$, Higher-power view of the same branch of the interneuron shown in $D$, with terminal swellings marked by small arrowheads. Other labels in $F$ are as in $D$. Scale bars: $A-E, 50 \mu \mathrm{m} ; F, 25 \mu \mathrm{m}$. 

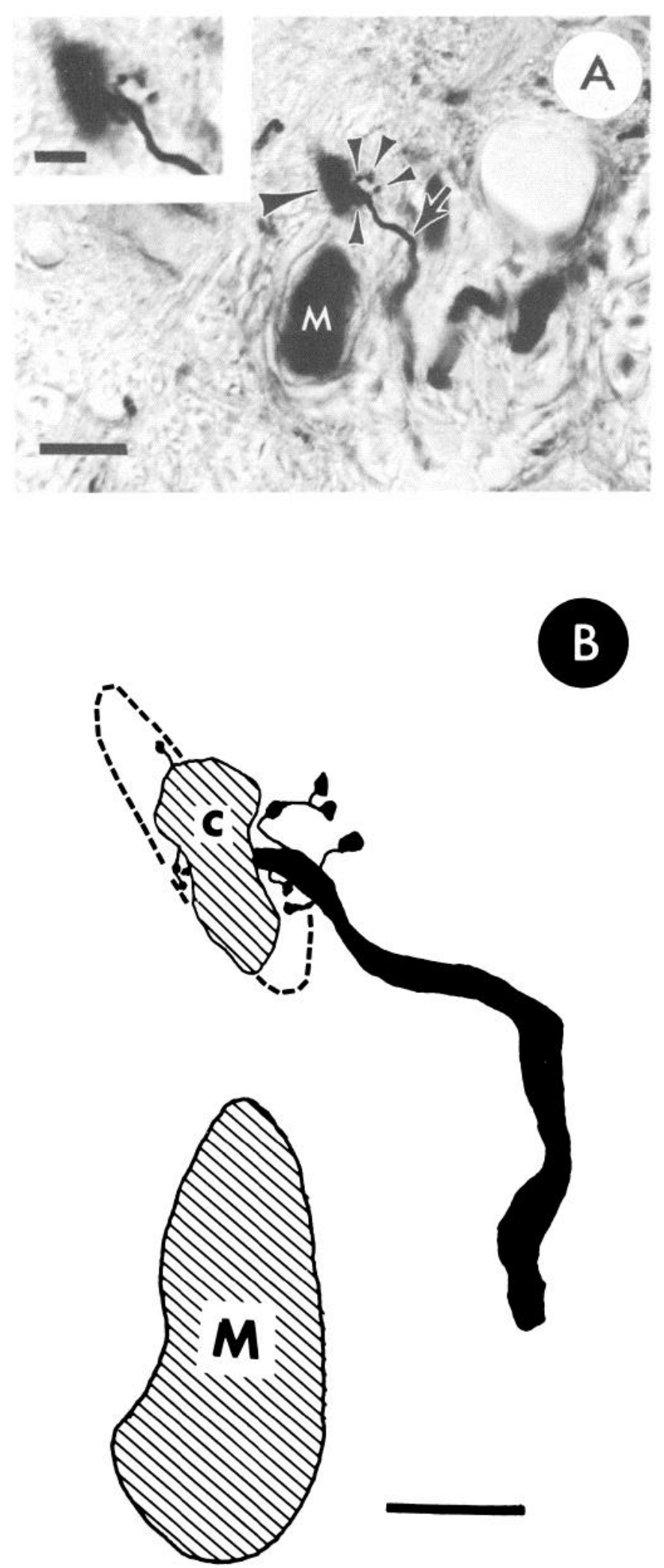

Figure 14. Terminal boutons of a crossing interneuron showing their relationships to both an M-axon collateral and a backfilled process of a primary motoneuron in a cross section of the cord. $A$, Branch of a crossing interneuron (arrow) with terminal boutons (small arrowheads) near the distal end of a collateral (large arrowhead) of the M-axon $(M)$ on the side of the cord contralateral to the M-axon that electrotonically excited the interneuron. Inset, Higher-power view of the terminal boutons. $B$, Camera lucida drawing of the section in $A$ showing some features the animal about its center of mass so that it points in a direction along which it can swim away from a potential threat (Eaton and Hackett, 1984). Under normal circumstances, the paired M-cells play a central role in the generation of this behavior. Their cell bodies are located on opposite sides of the hindbrain, and their axons cross in the brain to run down the length of the spinal cord on the side opposite to the soma. One of the 2 cells fires a single action potential in conjunction with every escape response in freely swimming goldfish, and the cells only fire in association with escapes (Zottoli, 1977). Selective activation of the M-axon in freely swimming fish also produces a behavior that is similar to the early phases of the C-start initiated by natural stimuli (Nissanov et al., 1986). Thus, the M-cell and its associated output connections play a critical role in the normal behavior.

The C-start has been well studied at both behavioral and cellular levels (see Faber and Korn, 1978, for review). Any account of its spinal circuitry must explain several characteristic features revealed by earlier studies. These include (1) the massive contraction of axial musculature on the side of the active M-axon (Diamond, 1971); (2) the sequential activation of several populations of motoneurons on the side of the active M-axon (Diamond, 1971); and (3) a powerful inhibition of motoneurons contralateral to the active M-axon (Yasargil and Diamond, 1968; Diamond, 1971). Until now, the anatomical and physiological studies designed to examine these features in fish have proceeded independently of one another, with inferences about physiology based on anatomy and vice versa (Yasargil and Diamond, 1968; Diamond and Yasargil, 1969; Diamond, 1971; Celio et al., 1979; Yasargil and Sandri, 1987). Our observations provide the first direct correlations between morphology and physiology; they confirm some suggestions in these earlier studies, refute others, and introduce new features of the circuitry that modify previous notions about its organization.

\section{Excitatory connections with motoneurons and descending interneurons}

Very early anatomical studies showed a close association between the M-axon and the ventral process of large motoneurons in the spinal cord of teleost fish (e.g., Beccari, 1919/20, and others reviewed by Diamond, 1971). These observations, which have been confirmed in several more recent studies (Diamond, 1971; Celio et al., 1979; Myers, 1985), suggested a physiological connection between the two. When intracellular recordings from motoneurons in fish were obtained, they revealed an excitatory connection between the $\mathrm{M}$-axon and a population of motoneurons that were, based on the location of the recording sites, most likely the large motoneurons located dorsally in the motor column (Yasargil and Diamond, 1968; Diamond, 1971).

Our combined morphological and physiological data from individual neurons confirm these earlier suggestions by providing strong, direct evidence that the $\mathrm{M}$-axon makes monosynaptic, chemical excitatory connections onto an ipsilateral population of large motoneurons. All but one of the motoneurons that received monosynaptic excitatory input were large, lay dor-

not visible in $A$ because of the narrow plane of focus. The dashed line outlines a portion of the ventral process of a primary motoneuron that was lightly stained by HRP applied to muscle and is only barely visible in the inset of $A$. This process is contacted by terminals of the crossing interneuron (shown solid black). The M-axon $(M)$ and its collateral $(c)$ are hatched. Scale bars: $A, 25 \mu \mathrm{m}$; inset and $B, 10 \mu \mathrm{m}$. 

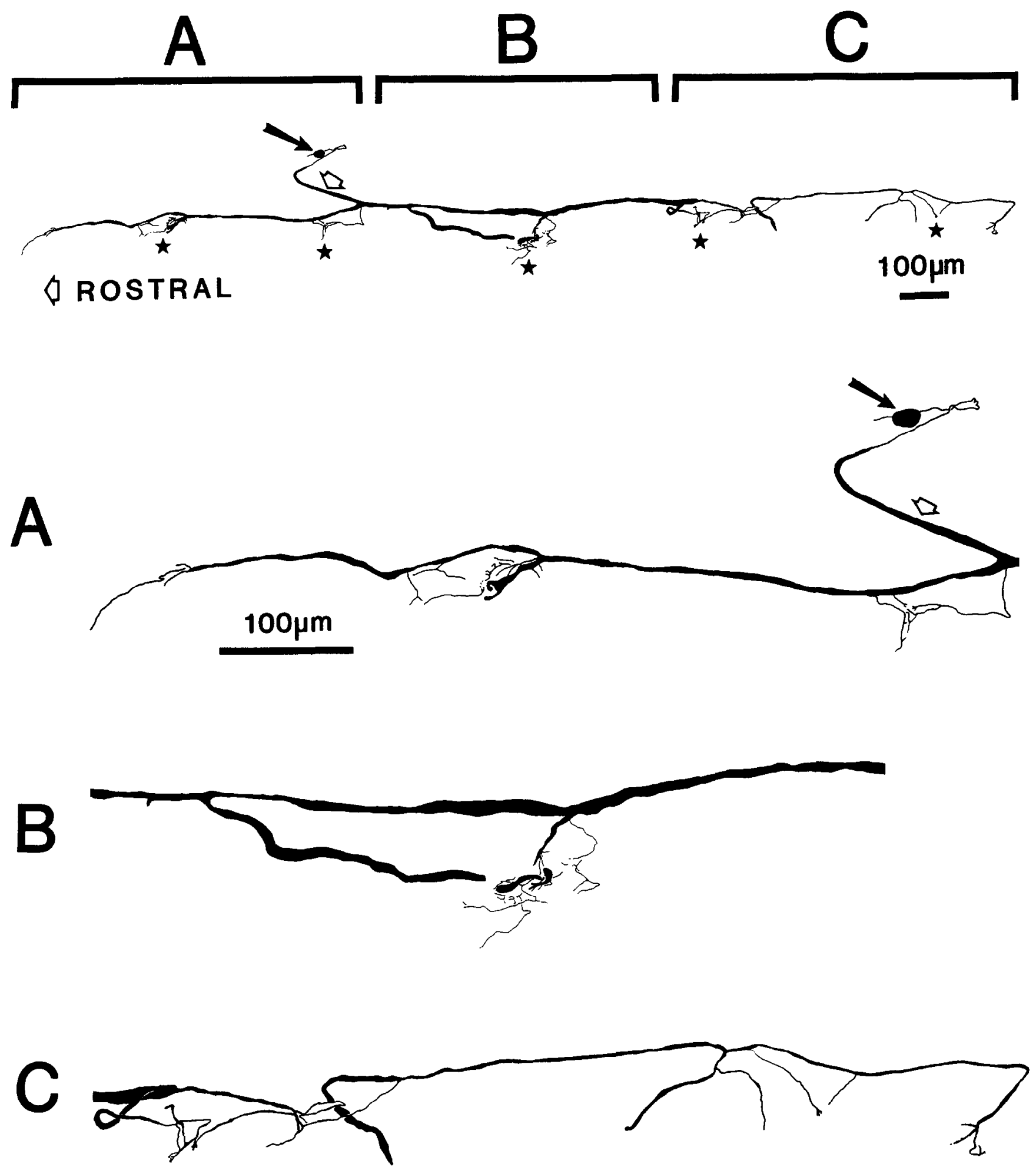

Figure 15. Reconstruction of a crossing interneuron in a horizontal view from above. Top panel, Complete view of the interneuron, with the indicated portions shown at higher power in $A-C$. Rostral is to the left; the left side of cord is at the bottom. Solid arrow marks the location of the soma, and the open arrow indicates the region where the major process of the interneuron crosses the cord. Stars mark regions where the contralateral processes of the interneuron terminate.

sal in the motor column, and had axons that ran medial to the $\mathrm{M}$-axon along their course to the ventral root. A great deal of information about these large motoneurons is now available as a consequence of recent studies of the relationship betwaen the motor column and the axial musculature in goldfish and ze- brafish (van Raamsdonk et al., 1983; Myers, 1985; Fetcho, 1986, 1987), as well as developmental studies of the motoneurons in zebrafish (Eisen et al., 1986; Myers et al., 1986; Westerfield et.al., 1986). The large motoneurons are called primary motoneurons because they develop first (Myers et al., 1986). There are only 
a few of them in each budy hemisegment (8-12 of the 130 motoneurons per hemisegment in goldfish: Fetcho, 1986; 3 of the 70 in zebrafish: Myers, 1985). They innervate exclusively the faster white muscle fiber type in the myomeres of goldfish (Fetcho, 1986). And finally, in zebrafish they have large peripheral fields in the musculature such that the 3 primary motoneurons of a hemisegment innervate 3 nonoverlapping regions in the myomere, with every white muscle fiber innervated by 1 of the 3 motoneurons (Westerfield et al., 1986). As a group, these neurons innervate every fast, white muscle fiber in the myomere, and the vast majority of muscle fibers in the myomeres are white. Therefore, the early excitation of these large motoneurons by the $\mathrm{M}$-axon would activate the bulk of the muscle fibers in the myomere and is probably largely responsible for the massive C-bend that occurs during the first stage of the startle response.

The only previous study of the physiology of the spinal connections of the M-axon in fish identified 2 physiologically defined units (A1 and A2) that were excited at short latency by the $\mathrm{M}$-axon and were thought to correspond to recordings from different regions of the primary motoneurons (Diamond and Yasargil, 1969; Diamond, 1971). One of these, the A2 units, could be fired antidromically from the ventral root, and Diamond and Yasargil suggested that they represented recordings from the somata or the ventral processes of the primary motoneurons. Our recordings from identified primary motoneurons are like their A2 units and confirm their earlier tentative identification. Diamond and Yasargil thought that the A1 units they recorded from, but could not fire antidromically from the ventral root, were spiking dendritic spines of primary motoneurons that received input from the $\mathrm{M}$-axon and relayed it to the main ventral process of the motoneuron through a highresistance "bridge" that served to isolate the M-axon/motoneuron contact from synaptic activity in the rest of the motoneuron. This high-resistance connection to the rest of the cell accounted for the inability to antidromically excite the Al units. These observations suggested that this was a rare instance in which intracellular recordings from a dendritic spine were possiblc, and they formed the basis of a theory about the function of dendritic spines (Diamond and Yasargil, 1969; Diamond et al., 1970).

Our data support an alternative explanation of the Al units that was mentioned, but not favored, by Diamond (1971). Our identified A1-like units are descending interneurons, not primary motoneurons. These units are almost certainly the Al units, based on the physiological similarities between the 2 and based on the locations of the recording sites of Diamond and Yasargil, which correspond with the locations of the major ventral processes of the interneurons and with sites where we could record from them. These interneurons are probably intermediary between the $\mathrm{M}$-axon and primary motoneurons, but not as stated specifically by Diamond (1971). Although they do have processes that contact dendrites and somata of primary motoneurons, our observations of direct contacts between the $\mathrm{M}$-axons and the primary motoneurons, as well as the short-latency connection between them, indicate that the earliest excitatory input to the primaries is direct, not relayed by the descending interneurons.

If these interneurons do not form the "connecting unit" of Diamond and Yasargil, then what role do they play in the circuitry? Our data provide some indirect evidence that they are excitatory. The morphology shows that they contact many mo- toneurons, including primary ones. Therefore, we might suspect that firing an $\mathrm{M}$-axon, which also fires descending interneurons, would produce a response in primary motoneurons that is related to the activation of the interneurons. The primary motoneurons received only excitatory inputs after firing the ipsilateral $\mathrm{M}$-axon, and their complex EPSPs typically had a late, prolonged depolarization that occurred with a delay roughly equal to the $1 \mathrm{msec}$ required by a disynaptic pathway. This late excitatory input might represent the response to the activation of the interneurons.

Diamond (1971) showed that several populations of motoneurons are activated by the $\mathbf{M}$-axon and proposed that the motoneurons excited late might be activated via an excitatory cascade in which firing the primary motoneurons excited other, secondary motoneurons through direct or indirect connections between the two. If, as our data suggest, the descending interneurons are excitatory, then they provide an alternative means for the late excitation of secondary motoneurons that does not require direct connections between primaries and secondaries. The interneurons contact a large number of secondary motoneurons as well as primary ones. Secondary motoneurons innervate both fast, white muscle fibers and tonic red ones (Fetcho, 1986). In the white muscle of zebrafish each fiber is innervated by several secondary motoneurons, along with a single primary one (Westerfield et al., 1986). If the arrangement in goldfish is similar, the late excitation of secondary motoneurons would provide supplemental excitation of muscle fibers already excited by primary motoneurons and might recruit additional muscle fibers if some primary motoneurons did not fire or fired but did not bring some of the muscle fibers they innervate to threshold. In this way the interneurons could contribute to the massive excitation of musculature. Because of the relatively restricted longitudinal distribution of their output, the interneurons might also serve a local role in the control of the populations of motoneurons activated during the startle response, particularly if the interneurons receive other inputs that affect their response to the M-axon.

\section{Activation of motoneurons during the C-start versus swimming in fish}

The activation of motoneurons during a C-start apparently differs considerably from their activation during swimming. Electromyographic studies of swimming in teleost fish show that the superficial, tonic, red muscle fibers are the first fibers active at the lowest swimming speeds, while the white fibers are activated at higher swimming speeds. (For reviews of this substantial literature, see Bone, 1978; Johnston, 1983; Fetcho, 1987). Because small, secondary motoneurons are the only ones that innervate the red muscle (Fetcho, 1986), they must be the first ones recruited during swimming. The larger, primary motoneurons innervating white fibers are probably also involved in swimming (Liu and Westerfield, 1988), but they are recruited only after the small ones, in general accord with the size principle established in other species (Henneman and Mcndcll, 1981). The M-cell system circumvents this normal activation according to size by the selective, monosynaptic excitation of the largest primary motoneurons innervating the fast white muscle fibers. Thus, the motoneurons excited earliest by the $\mathrm{M}$-axon are the largest ones, with the smaller secondary motoneurons activated via polysynaptic pathways. This initial activation of the largest motoneurons with the biggest peripheral fields is consistent with the functional role of the $\mathrm{M}$-cell system in the generation of 


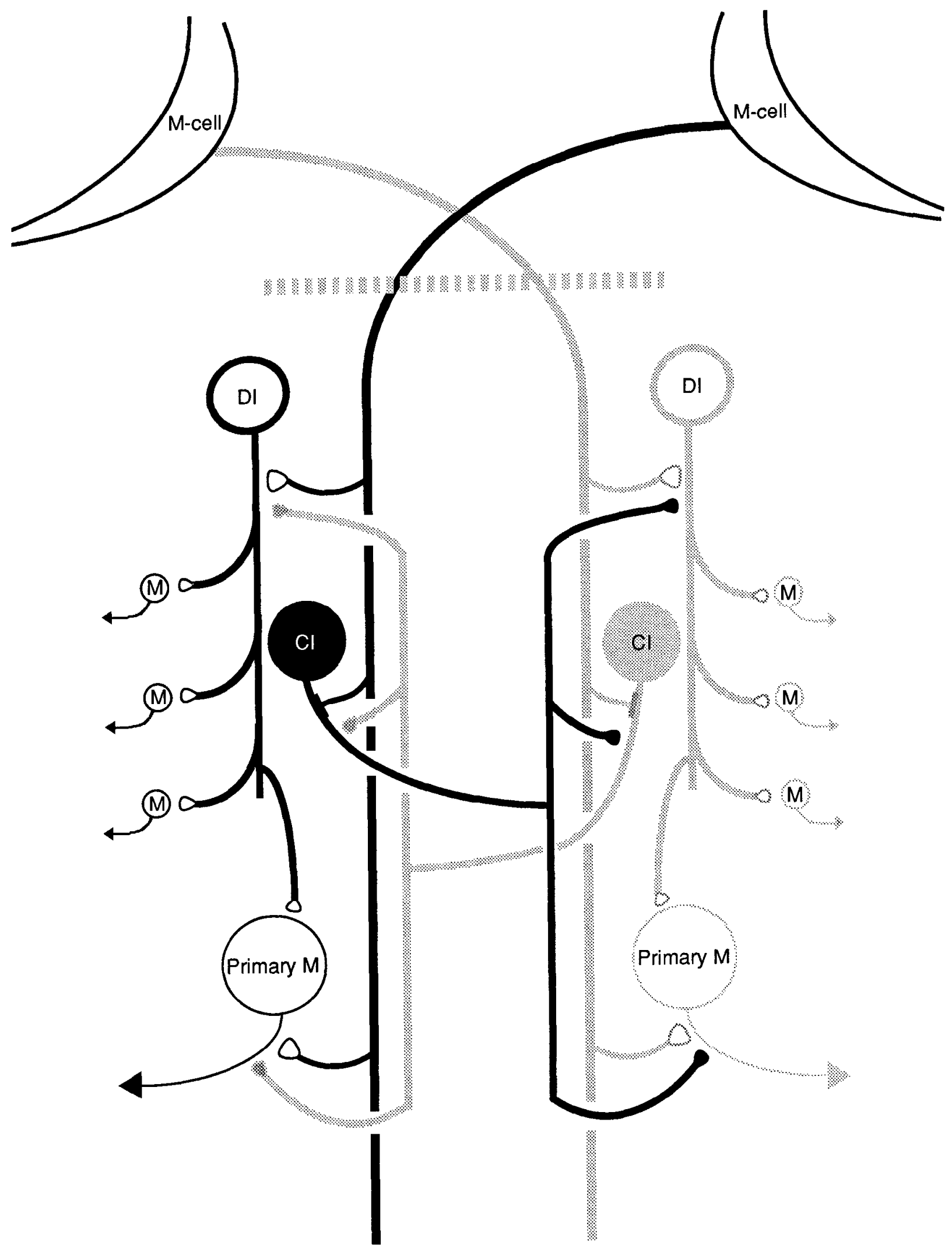

Figure 16. Diagram of the spinal circuitry of the M-cells. The left M-axon and the neurons excited by it are drawn in solid lines. The mirrorimage connections of the right $\mathrm{M}$-axon are lightly shaded. The left axon chemically excites (open terminals) ventral proccsscs of both primary motoneurons (Primary $M$ ), which innervate white muscle, and descending interneurons $(D I)$ that, in turn, contact both primary and secondary $(m)$ motoneurons. The connections from descending interneurons to motoneurons are probably excitatory (see text), although they have not yet been examined with pairwise intracellular recordings. The M-axon electrotonically excites (solid bar) an interneuron ( $C D$ ) which crosses the spinal cord 
rapid, forceful movements in potentially life-threatening situations.

\section{Crossed inhibition}

Diamond and Yasargil's earlier studies revealed a short-latency, crossed spinal inhibition by which a M-axon inhibited neurons on the opposite side of the cord (Yasargil and Diamond, 1968; Diamond, 1971). We have confirmed their observations and in addition have identified the neurons that are inhibited. Both the large primary motoneurons and the descending interneurons are chemically inhibited by the contralateral M-axon after a short latency that is only $0.1-0.2 \mathrm{msec}$ longer than the latency of monosynaptic excitation by the ipsilateral M-axon. This inhibition was most easily inverted by chloride injections when the recording site in motoneurons or interneurons was located ventrally, near the excitatory input from the ipsilateral M-axon, providing additional evidence for an earlier conclusion that the inhibitory inputs are located near the excitatory ones (Diamond, 1971).

The short latency of the inhibition prompted earlier workers to suggest that either collaterals from the M-axon crossed the cord to inhibit neurons on the opposite side directly, or that the M-axon is electrotonically coupled to an inhibitory interneuron that crosses the spinal cord (Diamond, 1971). Goldscheider et al. (1977) subsequently filled M-axons with Lucifer yellow and demonstrated that their collaterals did not cross the cord. Our HRP fills confirm this, and they also show that the inhibited primary motoneurons and descending interneurons do not have crossing processes. We are confident that our HRP fills would have revealed crossing processes if they were present because individual cells were filled over long distances $(4-6 \mathrm{~mm})$, and we could detect very fine filled processes. Furthermore, similar techniques successfully filled crossing processes in other neurons. Therefore, we can confidently rule out a direct connection between the M-axons and the contralateral neurons inhibited by them. These observations lead to the prediction of interneurons that are electrotonically excited by one $\mathbf{M}$-axon and cross the spinal cord to inhibit primary motoneurons and descending interneurons near where they receive their excitatory input from the other M-axon.

We propose that the crossing interneurons described in this paper are these predicted crossed inhibitory interneurons. All of the major features of these cells correspond with features of crossed inhibitory interneurons that were predicted prior to this work (Diamond, 1971; Goldscheider et al., 1977; Celio et al., 1979). These are the only cells in the spinal cord that we have found that are electrotonically excited by the M-axon. Their major (and usually only) process crosses the spinal cord, and its terminal branches show a remarkable correspondence with the collaterals of the contralateral M-axon, where the terminals are in a position to contact the ventral processes of primary motoneurons and descending interneurons near where the $\mathrm{M}$-axon collaterals excite them. In the one case in which we labeled motoneurons, a descending interneuron, and a crossing interneuron with HRP, the crossing interneuron had processes ap- posed to ventral processes of primary motoneurons and the descending interneuron. Thus, the crossing interneuron has processes in locations where they could produce the observed inhibition.

The crossing interneurons receive a chloride-dependent IPSP from the $\mathrm{M}$-axon contralateral to the one that electrotonically excites them. The IPSP could be revealed by chloride injections only when the recording site was located ncar the M-axon that was electrotonically coupled to the interneuron. The inhibitory contact with the crossing interneuron is therefore probably located near the electrotonic synapse, contralateral to the $\mathrm{M}$-axon that produced the inhibition. This, along with the absence of crossing processes of the $\mathrm{M}$-axon (Goldscheider et al., 1977) and the short, roughly monosynaptic, latency of the inhibition, leads to the conclusion that this inhibition is also mediated by an interneuron that is electrotonically excited by one $\mathrm{M}$-axon and that crosses the cord. Since the crossing interneurons described in this paper have processes located in regions where they could contact their homologs on the opposite side of the cord near their electrotonic junction with the M-axon, the simplest hypothesis consistent with the available data is that the crossed interneurons on opposite sides of the cord reciprocally inhibit one another.

Yasargil and Sandri (1987) have recently and independently identified a similar type of crossing interneuron in tench (Tinca tinca) by tracing the neurons from their electrotonic junction with the M-axon in serial semithin and thin sections. The gross morphology of the crossing interneurons in tench and goldfish is very similar, suggesting that they probably represent the same class of interneuron. The electron microscopic (EM) data of Yasargil and Sandri show that the crosscd interneuron forms synapses onto motoneurons and interneurons on the contralateral side of the cord, and these synapses have the morphology typical of inhibitory connections. Their EM data also show that crossed interneurons on one side contact contralateral crossed interneurons in the region of their electrotonic junctions with the M-axon. Our physiological data showing crossed inhibition of these interneurons are consistent with this EM work.

Yasargil and Sandri indicate that there is only one such crossed interneuron per spinal hemisegment; thus, it is a candidate for an individually identifiable neuron in a teleost spinal cord. While we cannot determine how many crossing interneurons there are per segment in goldfish from our data, the observation that the branches of individual interneurons extend over roughly one segment and terminate in association with nearly every collateral over the distance suggests that a single interneuron could inhibit all of the contralateral cells that receive excitatory input from the M-axon in that region of cord.

Together, the studies in tench and goldfish provide physiological, light microscopic, and EM data which indicate that these crossing interneurons are the crossed inhibitory interneurons in the M-cell circuitry. Since the crossed inhibition is blocked by strychnine (Diamond, 1971), if these interneurons mediate it, they are probably glycinergic.

The electrotonically excited crossing interneurons can account

and chemically inhibits ( flled terminals) both descending interneurons and primary motoneurons near where they receive their excitatory input from the other $\mathrm{M}$-axon. This crossing interneuron also chemically inhibits its homolog on the opposite side of the cord near its electrotonic input from the $\mathbf{M}$-axon. The primary motoneurons also receive a polysynaptic inhibition on their somata, which has not been included in the figure because its pathway is undefined. See text for details of the evidence for the various parts of the circuitry. Horizontal hatching at the top of the figure indicates the separation between supraspinal and spinal regions. 
for the shortest latency crossed inhibition; however, we also observed a previously unknown inhibitory input to the somata of primary motoneurons following activation of the contralateral M-axon. The latency of this input was more than $1 \mathrm{msec}$, consistent with at least 2 chemical synapses between the M-axon and the contralateral motoneurons. These data suggest that there is another population of inhibitory interneurons that may be chemically excited by the M-axon or by neurons excited by the $\mathrm{M}$-axon. Individual primary motoneurons are therefore inhibited by the contralateral $\mathrm{M}$-axon at 2 locations - ventrally, near the excitatory M-axon, through the electrotonically coupled, crossing interneurons and dorsally, in the region of the cell body, via a polysynaptic chemical pathway.

What roles might the different inhibitory pathways play? The short-latency pathway has becn vicwed as a means of preventing massive bilaterally synchronous activation of the axial musculature due to simultaneous firing of both $\mathrm{M}$-axons (Diamond, 1971). This view is consistent with both the ability of the crossed inhibition from one M-axon to block the activation of motoneurons by the contralateral $\mathrm{M}$-axon when the contralateral axon is fired somewhat later, and the complete absence of activity due to either M-axon when they are fired simultaneously, or near simultaneously (Diamond, 1971). The longer-latency somatic inhibition would, on the other hand, probably have little effect on the distant excitatory input from the M-axon. It may however serve to prevent excitation of motoneurons by non-M-axon inputs onto their dorsal dendrites and somata.

\section{Overview of the spinal circuitry of the C-start}

Our present understanding of the spinal network of the M-cells is summarized in Figure 16. The best evidence available concerns the connections between the M-axons and the various classes of spinal neurons. There have been no recordings from interneuron/motoneuron and interneuron/interneuron pairs, so there is no direct evidence about their physiology. However, the anatomical data just discussed show contacts between these neurons, and there is good circumstantial evidence about their physiological sign. Together, the available data lead to the following account of the network.

When one $\mathrm{M}$-axon fires, it massively excites ipsilateral musculature via monosynaptic connections with the primary motoneurons that innervate the faster white muscle fibers and polysynaptic excitation of motoneurons through descending interneurons. At the same time, it electrotonically excites a crossing interneuron that inhibits contralateral primary motoneurons, descending interneurons, and crossed inhibitory interneurons. The crossed inhibition apparently plays a dual role. It blocks monosynaptic and polysynaptic excitation of contralateral motoneurons, so that activation of contralateral muscle does not interfere with ipsilateral bending. The inhibition of the contralateral crossed inhibitory interneurons probably prevents their activation from blocking the excitation of ipsilateral motoneurons by the $\mathrm{M}$-axon. Both of these functions serve to maximize the excitation of ipsilateral motoneurons and minimize excitation of contralateral ones to produce the characteristic strong bend of the body and tail toward the side of an active M-axon.

Comparison of the spinal circuitry of the C-start in goldfish with the spinal circuitry for swimming in other anamniotes

One of the more important insights gained from recent detailed studies of the spinal circuitry for swimming in lampreys and anuran embryos (Buchanan, 1986; Grillner et al., 1986a, b; Roberts et al., 1986; Buchanan and Grillner, 1987) is that different groups of vertebrates have very similar spinal circuits with respect to both the morphology and the patterns of connectivity of the spinal neurons. Our studies of the spinal network of the M-axon suggest that these similarities extend to another major group of vertebrates (teleost fish) and even to a motor behavior that is considerably different from swimming.

The 2 populations of interneurons described in this paper are similar in morphology and connectivity to neurons having important roles in the swimming circuitry in lampreys and anuran embryos. A population of descending excitatory interneurons play an essential role in the maintenance of the swimming motor pattern by providing monosynaptic excitation of motoneurons (Dale and Roberts, 1985; Buchanan and Grillner, 1987). These interneurons are active in phase with motoneurons on the same side of the body and are inhibited by crossing interneurons when motoneurons on the opposite side of the body are active. The descending interneurons described in this paper are similar in that they descend in the cord, contact many motoneurons, and are most likely excitatory. They also are excited by the M-axon in conjunction with excitation of ipsilateral motoneurons and inhibited via a crossed spinal inhibition during the activation of contralateral motoneurons and descending interneurons by the other M-axon.

Reciprocal inhibitory interactions between the 2 sides of the cord are prominent in both C-start and swimming (Yasargil and Diamond, 1968; Dale, 1985; Grillner et al., 1986a, b). The pattern of inhibition in the 2 systems is similar, with activation of motoneurons and descending interneurons on one side accompanied by inhibition of the corresponding motoneurons and descending interneurons on the opposite side (Fig. 16). In both cases this crossed inhibition is mediated by crossing spinal interneurons, and these interneurons inhibit not only contralateral descending interneurons and motoneurons, but also inhibit the crossing interneurons on the opposite side of the cord. Thus, the distribution of the crossed inhibition and the neurons that probably mediate it in the 2 systems are similar.

In conclusion, although the spinal circuitry of the M-cell has not yet been examined as completely as the spinal circuitry for swimming in anurans and lampreys, we are, nevertheless, already struck by the similarities between the neurons and their connectivity in the 2 circuits. These similarities might be a consequence of the involvement of different, but very similar, networks in both C-starts and swimming. Alternatively, the 2 might use some of the same populations of interneurons. This would not be surprising because C-starts can occur during swimming and are often followed by swimming (Eaton et al., 1977; Eaton and Hackett, 1984). Thus, escapes must be integrated with preceding and subsequent swimming episodes, and the locus of these interactions might be spinal interneurons. The resolution of the roles of individual interneurons in different motor behaviors will be important in future studies. However, the data already indicate that many vertebrates have common arrangements of spinal circuitry, portions of which are used in such different motor behaviors as C-starts and swimming.

\section{References}

Adams, J. C. (1977) Technical considerations on the use of horseradish peroxidase as a neuronal marker. Neuroscience 2: 141-145.

Beccari, N. (1919/20) Peculiari modalita nelle connessioni di alcuni neuroni del sistema nervoso centrale dei Pesci. Ulteriori ricerche sulle collaterali delle fibre del Mauthner. Arch. Ital. Anat. 17: 239-283. 
Bone, Q. (1978) Locomotor muscle. In Fish Physiology, Vol. 7: Locomotion, W. S. Hoar and D. J. Randall, eds., pp. 361-424, Academic, New York.

Buchanan, J. T. (1986) Premotor interneurons in the lamprey spinal cord: Morphology, synaptic interactions and activities during fictive swimming. In Neurobiology of Vertebrate Locomotion, S. Grillner, P. S. G. Stein, H. Forssberg, and R. M. Herman, eds., pp. 321-333, Macmillan, London.

Buchanan, J. T., and S. Grillner (1987) Newly identified "glutamate interneurons" and their role in locomotion in the lamprey spinal cord. Science 236: 312-314.

Celio, M. R., E. G. Gray, and G. M. Yasargil (1979) Ultrastructure of the Mauthner axon collateral and its synapses in the goldfish spinal cord. J. Neurocytol. 8: 19-29.

Dale, N. (1985) Reciprocal inhibitory interneurones in the Xenopus embryo spinal cord. J. Physiol. (Lond.) 363: 61-70.

Dale, N., and A. Roberts (1985) Dual-component amino-acid-mediated synaptic potentials: Excitatory drive for swimming in Xenopus embryos. J. Physiol. (Lond.) 363: 35-59.

Diamond, J. (1971) The Mauthner cell. In Fish Physiology, Vol. 5, W. S. Hoar and D. J. Randall, eds., pp. 265-346, Academic, New York.

Diamond, J., and G. M. Yasargil (1969) Synaptic function in the fish spinal cord: Dendritic integration. In Mechanisms of Synaptic Transmission. Progress in Brain Research. Vol. 31, K. Akert and P. G. Waser, eds., pp. 201-209, Elsevier, New York

Diamond, J., E. G. Gray, and G. M. Yasargil (1970) The function of the dendritic spines: An hypothesis. In Excitatory Synaptic Mechanisms, P. Anderson and J. K. S. Jansen, eds., pp. 213-222, Scandinavian University Books, Oslo.

Eaton, R. C., and J. T. Hackett (1984) The role of the Mauthner cell in fast-starts involving escape in teleost fishes. In Neural Mechanisms of Startle Behavior, R. C. Eaton, ed., pp. 213-266, Plenum, New York.

Eaton, K. C., K. A. Bombardieri, and D. Meyer (1977) The Mauthner initiated startle response in teleost fish. J. Exp. Biol. 66: 65-81.

Eisen, J. S., P. Z. Myers, and M. Westerfield (1986) Pathway selection by growth cones of identified motoneurones in live zebrafish embryos. Nature 320: 269-271.

Faher, D. S., and H. Korn (1978) Neurobiology of the Mauthner Cell, Raven, New York.

Fetcho, J. R. (1986) The organization of the motoneurons innervating the axial musculature of vertebrates. I. Goldfish (Carassius auratus) and mudpuppies (Necturus maculosus). J. Comp. Neurol. 249: 521550.

Fetcho, J. R. (1987) A review of the organization and evolution of motoneurons innervating the axial musculature of vertebrates. Brain Res. Rev. 12: 243-280.

Fetcho, J. R., and D. S. Faber (1986a) Synaptic connections between the Mauthner axon and identified motoneurons and interneurons in the caudal spinal cord of goldfish. Soc. Neurosci. Abstr. 12: 790.

Fetcho, J. R., and D. S. Faber (1986b) Motoneurons innervating white muscle are monosynaptically excited by the Mauthner axon during a Mauthner-initiated tail-flip in goldfish. Am. Zool. Abstr. 26: 82A

Fetcho, J. R., and D. S. Faber (1987a) Spinal interneurons that may mediate the crossed inhibition during a Mauthner-initiated escape behavior in goldfish. Soc. Neurosci. Abstr. 13: 823.

Fetcho, J. R., and D. S. Faber (1987b) Similarities between the spinal circuitry of the C-start in goldfish and the spinal circuitry for swimming in other anamniotes. Am. Zool. Abstr. 27: 167A.

Funch, P. G., M. R. Wood, and D. S. Faber (1984) Localization of active sites along the myelinated goldfish Mauthner axon: Morphological and pharmacological evidence for saltatory conduction. J. Neurosci. 4: 2397-2409.
Goldscheider, H. G., H. R. Luscher, and G. M. Yasargil (1977) Disynaptischer Weg der durch die Mauthneraxon-Erregung verursachten Hemmung spinaler Motoneurone. Experientia 33: 780.

Grillner, S., L. Broden, K. Sigvardt, and N. Dale (1986a) On the spinal network generating locomotion in the lamprey: Transmitters, membrane properties and circuitry. In Neurobiology of Vertebrate Locomotion, S. Grillner, P. S. G. Stein, H. Forssberg, and R. M. Herman, eds., pp. 335-352, Macmillan, London.

Grillner, S., P. S. G. Stein, D. G. Stuart, H. Forssberg, and R. M. Herman, Eds., (1986b) Neurobiology of Vertebrate Locomotion, Macmillan, London.

Henneman, E., and L. M. Mendell (1981) Functional organization of motoneuron pool and its inputs. In Handbook of Physiology, Sect. 1: The Nervous System, Vol. 2, Motor Control, Part 1, V. B. Brooks, ed., pp. 423-507, American Physiological Society, Bethesda, MD.

Johnston, I. A. (1983) Dynamic properties of fish muscle. In Fish Biomechanics, P. W. Webb and D. Weihs, eds., pp. 37-67, Praeger, New York.

Liu, D., and M. Westerfield (1988) Function of identified motoneurones and coordination of primary and secondary motor systems during zebrafish swimming. J. Physiol. (Lond.) (in press).

Llinás, R. R., and J. E. Heuser, Eds. (1977) Depolarization-release coupling systems in neurons. In Neurosciences Research Program Bulletin, MIT Press, Boston.

Myers, P. Z. (1985) Spinal motoneurons of the larval zebrafish. J. Comp. Neurol. 236: 555-561.

Myers, P. Z., J. S. Eisen, and M. Westerfield (1986) Development and axonal outgrowth of identified motoneurons in the zebrafish. J. Neurosci. 6: 2278-2289.

Nissanov, J., R. C. Eaton, and R. DiDomenico (1986) Parallel activation within a reticulospinal command system. Soc. Neurosci. Abstr. 12: 387

Roberts, A., S. R. Soffe, and N. Dale (1986) Spinal interneurons and swimming in frog embryos. In Neurobiology of Vertebrate Locomotion, S. Grillner, P. S. G. Stein, H. Forssberg, and K. M. Herman, eds., pp. 279-306, Macmillan, London.

van Raamsdonk, W., W. Mos, M. J. Smit-Onel, W. J. van der Laarse, and R. Fehres (1983) The development of the spinal motor column in relation to the myotomal muscle fibres in the zebrafish (Brachydanio rerio). I. Posthatching development. Anat. Embryol. 167: 125139.

Webb, P. W. (1978) Temperature effects on acceleration of rainbow trout Salmo gairdneri. J. Fish Res. Board Can. 35: 1417-1422.

Westerfield, M., J. V. McMurrary, and J. S. Eisen (1986) Identified motoneurons and their innervation of axial muscles in the zebrafish. J. Neurosci. 6: 2267-2277.

Yasargil, G. M., and J. Diamond (1968) Startle-response in teleost fish: An elementary circuit for neural discrimination. Nature 220 : 24I-243.

Yasargil, G. M., and C. Sandri (1987) Morphology of the Mauthner axon inhibitory system in tench (Tinca tinca L.) spinal cord. Neurosci. Lett. 81: 63-68.

Yasargil, G. M., N. G. Greeff, H. R. Luescher, K. Akert, and C. Sandri (1982) The structural correlate of saltatory conduction along the Mauthner axon in the tench (Tinca tinca L.): Identification of nodal equivalents at the axon collaterals. J. Comp Neurol. 212: 417-424.

Zottoli, S. J. (1977) Correlation of the startle reflex and Mauthner cell auditory responses in unrestrained goldfish. J. Exp. Biol. 66: 243254.

Zottoli, S. J. (1978) Comparative morphology of the Mauthner cell in fish and amphibians. In Neurobiology of the Mauthner Cell, D. S. Faber and H. Korn, eds., pp. 13-45, Raven, New York. 